\title{
Hepatic JAK2 protects against atherosclerosis through circulating IGF-1
}

\author{
Tharini Sivasubramaniyam, ${ }^{1,2}$ Stephanie A. Schroer, ${ }^{1}$ Angela Li, ${ }^{1,3}$ Cynthia T. Luk, ${ }^{1,2}$ Sally Yu Shi, ${ }^{1,2}$ \\ Rickvinder Besla, ${ }^{1,4}$ David W. Dodington, ${ }^{1}$ Adam H. Metherel, ${ }^{5}$ Alex P. Kitson, ${ }^{5}$ Jara J. Brunt, ${ }^{1,2}$ \\ Joshua Lopes, ${ }^{4}$ Kay-Uwe Wagner, ${ }^{6}$ Richard P. Bazinet, ${ }^{5}$ Michelle P. Bendeck, ${ }^{4,7}$ Clinton S. Robbins, $, 3,3,4$ \\ and Minna Woo $0^{1,2,3,8}$ \\ 'Toronto General Hospital Research Institute, University Health Network, Toronto, Ontario, Canada. ${ }^{2}$ Institute of Medical \\ Science, ${ }^{3}$ Department of Immunology, ${ }^{4}$ Department of Laboratory Medicine and Pathobiology, ${ }^{5}$ Department of Nutritional \\ Sciences, University of Toronto, Toronto, Ontario, Canada. ${ }^{6}$ Eppley Institute for Research in Cancer and Allied Diseases and \\ the Department of Biochemistry and Molecular Biology, University of Nebraska Medical Center, Omaha, Nebraska, USA. \\ 'Department of Physiology, University of Toronto, Toronto, Ontario, Canada. ${ }^{8}$ Division of Endocrinology and Metabolism, \\ Department of Medicine, University Health Network, University of Toronto, Toronto, Ontario, Canada.
}

\begin{abstract}
Atherosclerosis is considered both a metabolic and inflammatory disease; however, the specific tissue and signaling molecules that instigate and propagate this disease remain unclear. The liver is a central site of inflammation and lipid metabolism that is critical for atherosclerosis, and JAK2 is a key mediator of inflammation and, more recently, of hepatic lipid metabolism. However, precise effects of hepatic Jak2 on atherosclerosis remain unknown. We show here that hepatic Jak2 deficiency in atherosclerosis-prone mouse models exhibited accelerated atherosclerosis with increased plaque macrophages and decreased plaque smooth muscle cell content. JAK2's essential role in growth hormone signalling in liver that resulted in reduced IGF-1 with hepatic Jak2 deficiency played a causal role in exacerbating atherosclerosis. As such, restoring IGF-1 either pharmacologically or genetically attenuated atherosclerotic burden. Together, our data show hepatic Jak2 to play a protective role in atherogenesis through actions mediated by circulating ICF-1 and, to our knowledge, provide a novel liver-centric mechanism in atheroprotection.
\end{abstract}

Conflict of interest: The authors have declared that no conflict of interest exists.

Submitted: March 7, 2017

Accepted: June 6, 2017

Published: July 20, 2017

\section{Reference information:}

JCI Insight. 2017;2(14):e93735.

https://doi.org/10.1172/jici.

insight.93735.

\section{Introduction}

Cardiovascular disease (CVD) is the leading cause of morbidity and mortality worldwide, despite advances in surveillance and treatment strategies. Atherosclerosis, the major pathology in CVD, is a complex multifactorial disease of the large arteries in part caused by dyslipidemia $(1,2)$, with inflammation emerging to have a major role in the underlying mechanisms $(3,4)$. To date, molecular mechanisms that instigate and propagate atherosclerosis remain unclear.

Recent studies have suggested the liver to contribute significantly to the inflammatory process during atherogenesis. For example, proinflammatory mediators such as the IL-6 family of cytokines can stimulate hepatic acute phase response via the glycoprotein 130 (gp130)/JAK/STAT signaling pathway, resulting in hepatic acute-phase protein release, such as C-reactive protein and serum amyloid A, which are implicated in disease progression (5-7). Thus, liver-derived proteins may play an important role in the development and progression of atherosclerosis.

The JAK/STAT pathway is a critical regulator of inflammatory processes and transmits extracellular signals from growth factors and cytokines at the plasma membrane to the nucleus in order to activate or repress transcription of specific target genes (8-11). Given the critical link between inflammation and atherosclerosis $(12,13)$, the JAK/STAT signaling pathway has also been implicated in atherogenesis and the manifestation of vascular disease (14-18). Various factors are described linking activation of the JAK/ STAT signaling pathway to vascular diseases, including angiotensin II-mediated neointima formation (18), vasoconstriction, and hypertension (19); oxidized phospholipid-induced transcription of IL-8, an important mediator of monocyte transmigration and retention into the vessel wall; and IL-6-mediated transcription of hepatic acute phase proteins $(20,21)$. We and others have previously demonstrated a pivotal role of hepatic Jak2 in lipid metabolism, whereby deletion of Jak2 in hepatocytes leads to profound spontaneous 
hepatic steatosis $(22,23)$. Importantly, we have shown that this steatosis was not associated with systemic insulin resistance or glucose intolerance, even after high-fat diet feeding. Given the role of the liver in lipoprotein metabolism and inflammation, both well-known atherogenic risk factors, our goal was to assess the essential role of hepatic Jak2 in atherogenesis and disease progression.

We and others have previously shown that JAK2 is required for growth hormone $(\mathrm{GH})$ signaling in the liver, such that hepatic Jak2-deficient mice have significantly reduced levels of circulating IGF-1 (22, 23). IGF-1 is both an endocrine and autocrine/paracrine growth factor that exerts pleiotropic effects on different cells types involved in atherogenesis. As such, it is a challenge to delineate the precise contribution of IGF-1 by a specific cell type in atherogenesis. For instance, in endothelial cells, IGF-1 has been shown to have an atheroprotective role through reduction in oxidative stress and induction of endothelial NOS activity $(24,25)$. In cultured macrophages, however, IGF-1 can enhance chemotactic migration, expression of $\mathrm{TNF} \alpha$, and LDL uptake $(26,27)$, which can promote atherosclerosis. In smooth muscle cells, IGF-1 could have either a proatherogenic or an antiatherogenic effect, depending on the stage of atherosclerosis. At early stages, IGF-1 has been shown to promote smooth muscle cell proliferation and migration, leading to neointimal formation, which results in proatherogenic effects $(28,29)$. At later stages, on the other hand, IGF-1 has been shown to promote plaque stability by promoting survival pathways of the vascular smooth muscle cells (30). The role of IGF-I in atherogenesis in animal models is also unclear, with some models showing atherosclerotic plaque-stabilizing effects and others showing exacerbating effects (31-34). The question still remains what critical role hepatic Jak2 has on atherosclerosis and whether Jak2's essential role in $\mathrm{GH}$ signaling is central to atherogenesis.

In this study, we show that atherosclerosis-prone mouse models with hepatic Jak2 deficiency have profound fatty liver and significantly accelerated atherosclerosis. These findings were not associated with changes in glucose tolerance, insulin sensitivity, circulating cholesterol, or systemic inflammation. To assess whether reduced Igf1 production by hepatocytes that occurred as a consequence of diminished GH signaling had a causal role in accelerating atherosclerosis, we restored IGF-1 pharmacologically through continuous systemic infusion or genetically by overexpressing IGF-1 in hepatocytes of these Jak2-deficient mice. Intriguingly, we found significant attenuation in atherosclerotic plaque burden when IGF-1 was restored in hepatic Jak2-deficient mice, supporting the causal role of reduced IGF-1 in the increased atherosclerotic burden. To our knowledge, our results provide a novel liver-centric mechanism in the maintenance of vascular health.

\section{Results}

Hepatic Jak2 deficiency leads to accelerated atherosclerosis. To assess the essential role of hepatic Jak2 on atherosclerosis, we generated atherosclerosis-prone $A l b-C r e^{+} J a k 2^{f l f l} A p o E^{-/-}$mice, referred to herein as $L-J a k 2^{-1-} A p o E^{-/-}$, and $\mathrm{Alb}-\mathrm{Cre}^{+} \mathrm{Jak2}^{+/+} \mathrm{ApoE^{-/- }}$ control littermates, referred to herein as $L-J a k 2^{+/+} A p o E^{-/-}$, and placed them on an atherogenic diet for 12 weeks. Intriguingly, $L-J a k 2^{-1-} A p o E^{-1-}$ mice had a marked increase in atherosclerosis, with over a 2-fold increase in atherosclerotic plaque burden compared with control littermates, as assessed by oil red $\mathrm{O}(\mathrm{ORO})$ staining of the descending aorta (Figure 1A). Similarly, longitudinal sections of the lesser curvature of the aortic arch showed over a 2-fold increase in lesion area in $\mathrm{L}-\mathrm{Jak2^{-1- }} A \mathrm{poE} \mathrm{E}^{-/-}$mice compared with control littermates (Figure 1B). These atherosclerotic lesions were advanced, showing enlarged necrotic cores (Figure 1B), significantly increased macrophage content as evidenced by Mac3-immunopositive areas (Figure 1C), and a decrease in the percentage of $\alpha$-smooth muscle actin-positive ( $\alpha$-SMA-positive) cells within the plaques that represent stability (Figure 1D). Collectively, these data suggest that hepatic Jak2 plays a protective role against development and progression of atherosclerosis, such that mice lacking hepatic Jak2 develop accelerated atherosclerosis with a number of features of advanced plaque progression. Indeed, even on a standard chow diet, L-Jak2 ${ }^{-1-} \mathrm{ApoE}^{-/-}$mice spontaneously developed significantly more atherosclerotic plaques compared with control littermates, as evidenced by en face analysis of the descending aorta (Supplemental Figure 1A; supplemental material available online with this article; https://doi.org/10.1172/jci.insight.93735DS1) and cross-section of the lesser curvature of the aortic arch (Supplemental Figure 1B).

Profound hepatic steatosis in L-Jak2 $2^{-1} A p o E^{-/-}$mice. Similar to hepatic Jak2-deficient mice without the ApoE-null mutation (23), L-Jak2 $2^{--} A p o E^{-/-}$mice also exhibited profound hepatic steatosis, as evidenced by $\mathrm{H} \& \mathrm{E}$ and ORO stains showing increased intrahepatic lipid accumulation compared with control littermates (Figure 2A) with an increase in liver triglyceride (TG) content (Figure 2B). This was associated with hepatomegaly, as shown by increased liver weight (Figure 2C). Furthermore, markers of liver injury, serum 
A

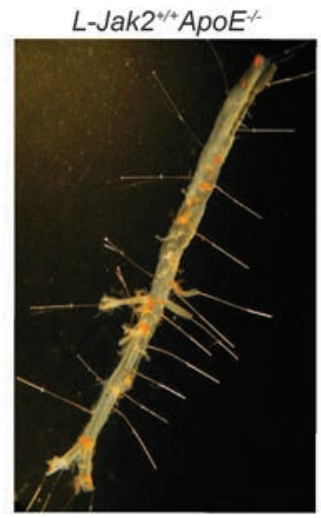

B

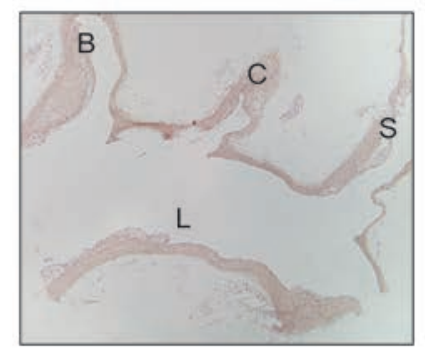

C

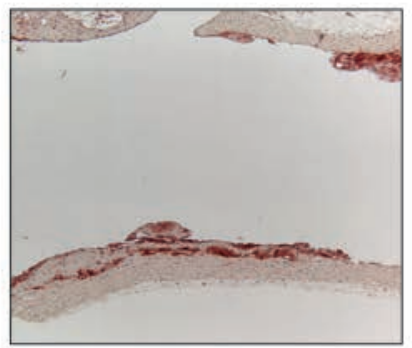

D

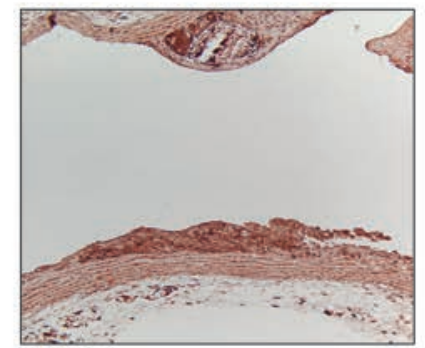

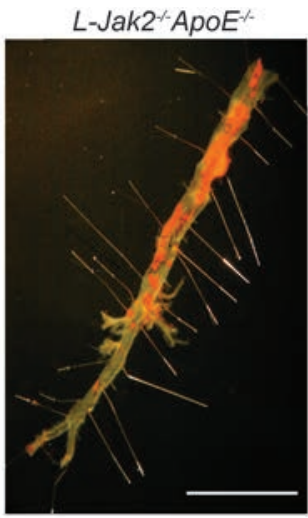
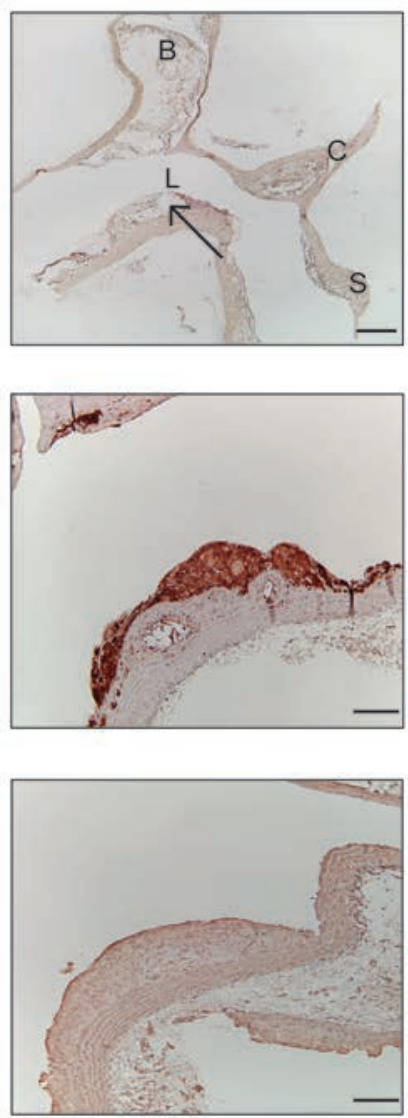

L-Jak2 $2^{+/+} A p o E^{--}$

L-Jak2'ApoE
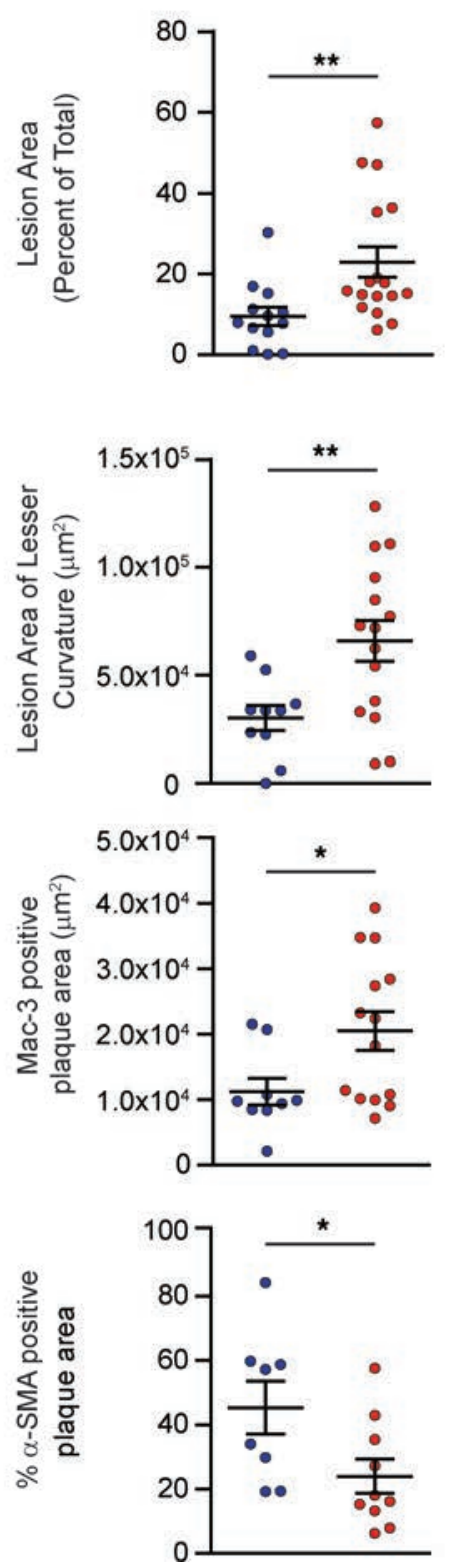

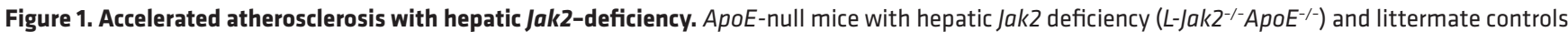
$\left(L-J a \mathrm{kZ}^{+/+} \mathrm{ApoE}^{-/-}\right)$were fed an atherogenic diet containing $0.2 \%$ cholesterol for 12 weeks, starting at 6 weeks of age. (A) Representative photographs of en face oil red $\mathrm{O}(\mathrm{ORO})$ staining and quantification of atherosclerotic plaque area in descending aortas of $L-J a k 2^{-{ }^{--}} A p o E^{-/-}$mice $(n=17)$ and control $L-J a k 2^{+/+} A-$ $p o E^{-/-}$mice $(n=13)$. Scale bar: $1 \mathrm{~cm}$. (B) Representative images of longitudinal sections from the aortic arch of $L-J a k 2^{-/-} A p o E^{-/-}$mice $(n=15)$ and control L-Jak $2^{+/+} A p o E^{-/-}$mice $(n=10)$ stained with H\&E and quantification of lesion size at the lesser curvature. B, brachiocephalic artery; C, left common carotid; $\mathrm{S}$, subclavian artery; $\mathrm{L}$, lesser curvature. Arrow indicates necrotic core. Scale bar: $200 \mu \mathrm{m}$. (C and D) Representative images of the lesser curvature of

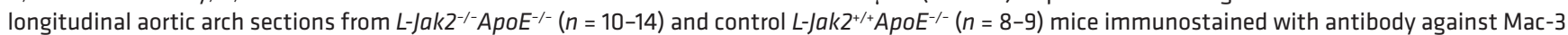
and $\alpha$-smooth muscle actin $(\alpha$-SMA) and quantification of positively stained area expressed as an absolute number or percentage. Scale bars: $100 \mu \mathrm{m}$. In each of the panels, each dot in the scatter plot indicates an individual animal. Data represent mean $\pm S E M$. Differences between groups were analyzed for statistical significance by Student unpaired $t$ test. ${ }^{*} P<0.05,{ }^{* *} P<0.01$.

aspartate aminotransferase (AST) and alanine aminotransferase (ALT), were increased compared with controls, consistent with increased inflammation and fatty liver, respectively (Figure 2D). Furthermore, mRNA expression for markers of inflammation, including Tnfa, Il6, and Ifng, and markers of fibrosis, including Tgfb, aSma, and Procollagen1, were also increased in liver tissue of $L-J a k 2^{-1-} A p o E^{-1-}$ mice compared with controls (Figure 2E). Inflammation appeared to be isolated within the liver tissue, as circulating levels of 
A

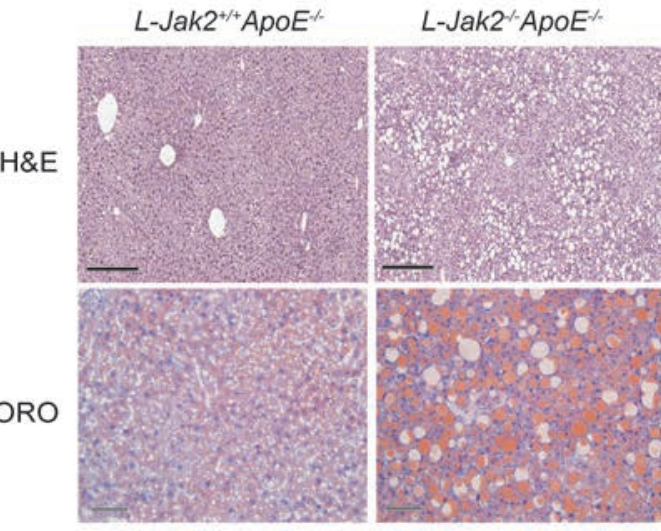

B

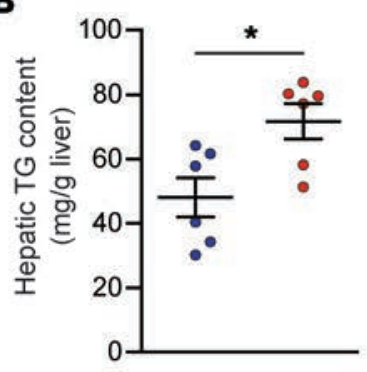

L-Jak2 ${ }^{+/+} A p o E^{-}$

L-Jak2 ApoE

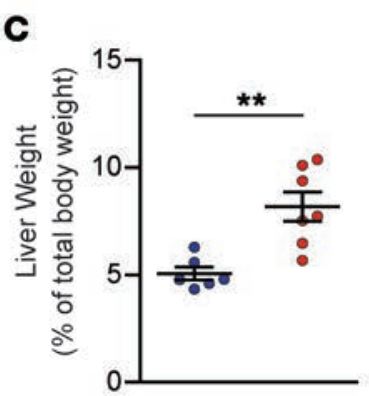

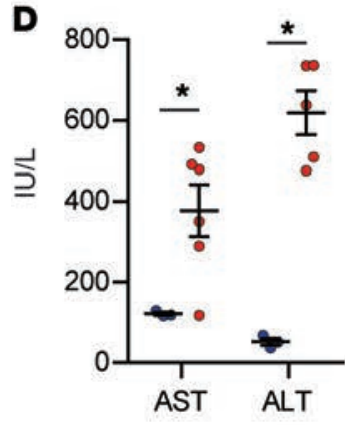

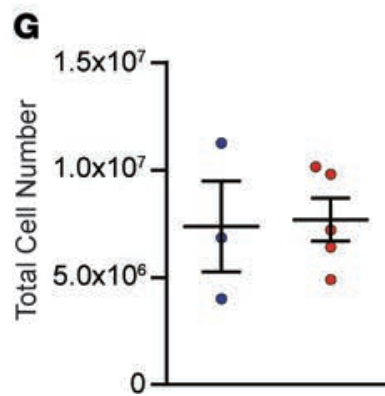

E

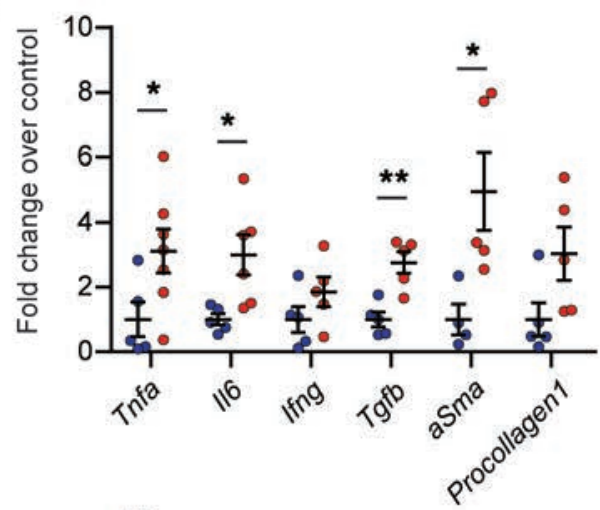

H

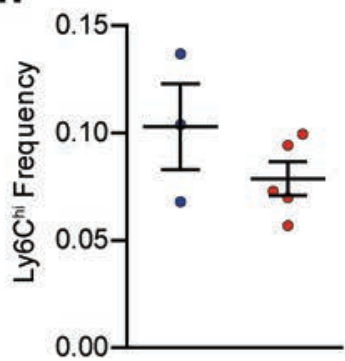

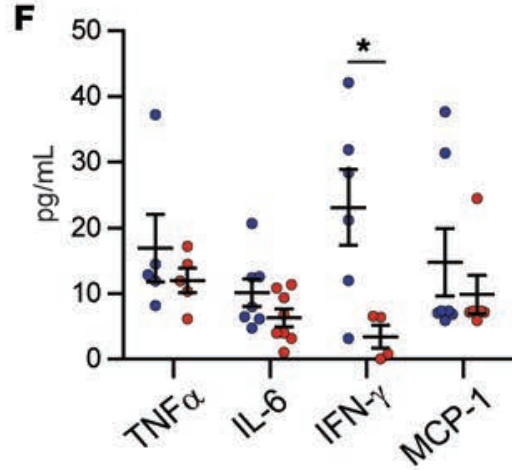

I

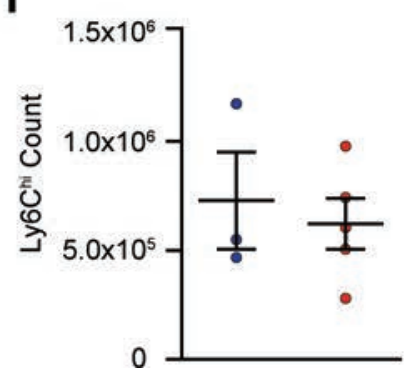

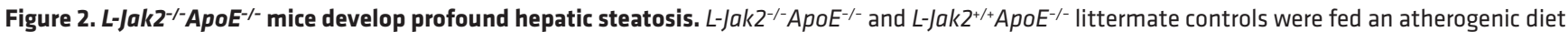
containing $0.2 \%$ cholesterol for 12 weeks, starting at 6 weeks of age. (A) Representative images of H\&E and oil red 0 (ORO) staining of liver sections from

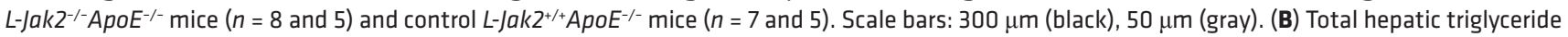

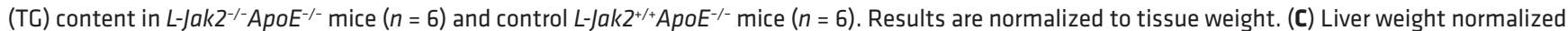

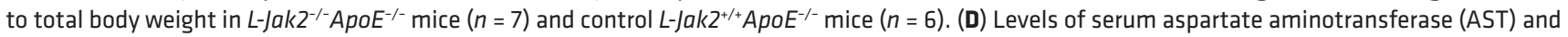

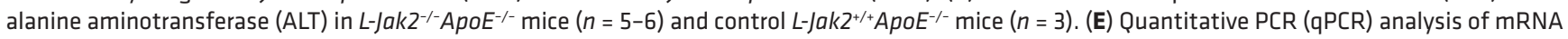

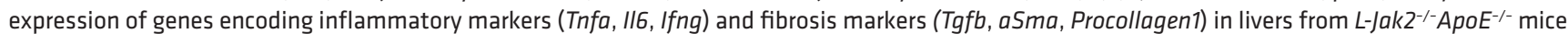
$(n=5-7)$ and control $L-J a k 2^{++} A p o E^{-/-}$mice $(n=4-5)$. Values are normalized to 185 mRNA levels and presented as fold change over control group. aSma,

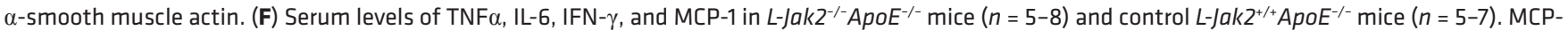

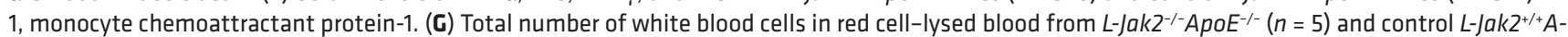
$p o E^{-/-}$mice $(n=3)$. (H and I) Frequency and absolute numbers of Ly6C $\mathrm{C}^{\mathrm{hi}}$ monocytes in red cell-lysed blood from $L-J a k 2^{-/-} A p o E^{-/-}$mice $(n=5)$ and control L-Jak $2^{+/+} A p o E^{-/-}$mice $(n=3)$ using flow cytometry. Ly6C ${ }^{\text {hi }}$ monocytes were defined based on CD115+Ly6ChiLy6G- expression. In each of the panels, each dot in the scatter plot indicates an individual animal. Data represent mean \pm SEM. Differences between groups were analyzed for statistical significance by Student unpaired $t$ test. ${ }^{*} P<0.05,{ }^{* *} P<0.01$.

these inflammatory cytokines, as well as monocyte chemoattractant protein-1 (MCP-1), were not elevated in hepatic Jak2-deficient mice compared with control littermates (Figure 2F). In fact, there was a general trend toward a decrease in these circulating cytokines, with serum IFN- $\gamma$ being significantly decreased in L-Jak2 ${ }^{-1} A p o E^{-1-}$ mice compared with controls (Figure 2F). Mice were also assessed for circulating leukocyte counts, and hepatic Jak2 deficiency did not result in significant differences (Figure 2G). A subpopu- 

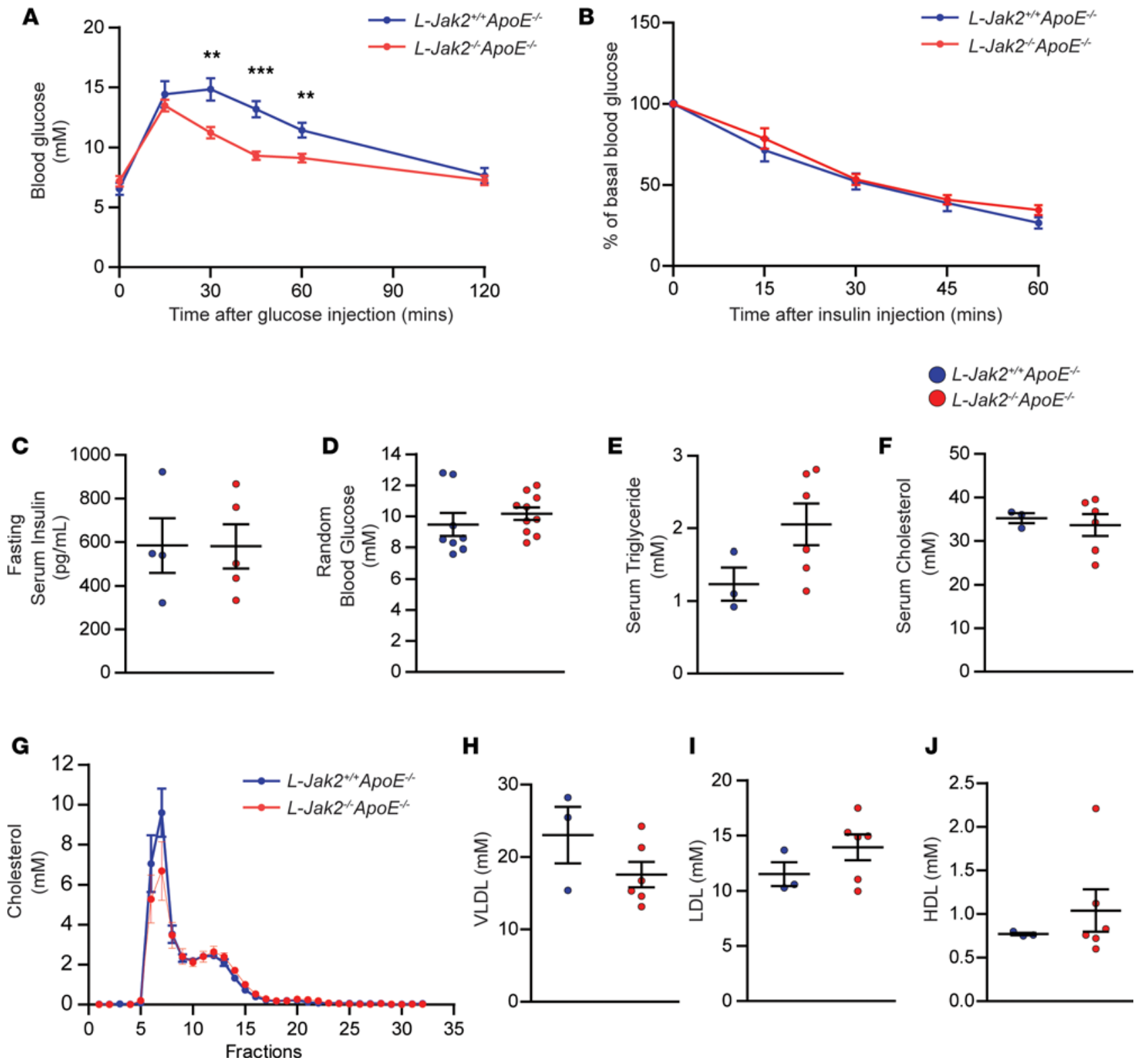

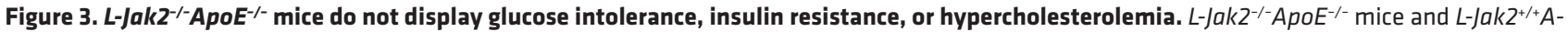
poE $E^{-/-}$littermate controls were fed an atherogenic diet containing $0.2 \%$ cholesterol for 12 weeks, starting at 6 weeks of age. (A) Glucose tolerance test in overnight-fasted $L_{-} J a k 2^{-/-} A p o E^{-/-}$mice $(n=14)$ and control $L-J a k Z^{+/+} A p o E^{-/-}$mice $(n=11)$. Mice received glucose $(1 \mathrm{~g} / \mathrm{kg})$ i.p. and blood glucose was measured sequentially for 120 minutes. (B) Insulin tolerance test in 4 hour-fasted $L-J a k 2^{-/-} A p o E^{-/-}$mice $(n=14)$ and control $L$-Jak $2^{+/+} A p o E^{-/-}$mice $(n=10)$. Mice received insulin $(0.75$ units $/ \mathrm{kg}$ ) i.p. and blood glucose was measured sequentially for 60 minutes. Data are expressed as a percentage of basal (fasting) glucose. (C) Fasting serum insulin levels from $L-J a k 2^{-/-} A p o E^{-/-}$mice $(n=5)$ and control $L-J a k 2^{+/+} A p o E^{-/-}$mice $(n=4)$. (D) Random blood glucose from

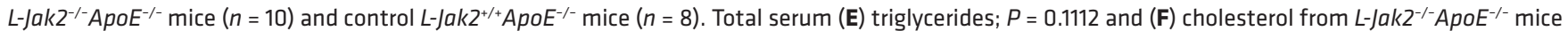

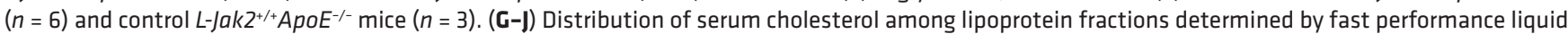

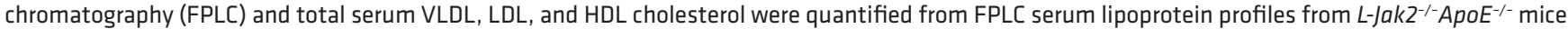
$(n=6)$ and control $L-J a k Z^{+/+} A p o E^{-/-}$mice $(n=3)$. In panels displaying scatterplots, each dot in the scatter plot indicates an individual animal. Data represent mean \pm SEM. Differences between groups were analyzed for statistical significance by Student unpaired $t$ test. ${ }^{* *} P<0.01,{ }^{* * *} P<0.001$.

lation of circulating Ly6 $\mathrm{C}^{\text {hi }}$ monocytes that are proinflammatory and often increased with atherosclerosis (35) were also not different between $L-J a k 2^{-1-} \mathrm{ApoE}^{-/-}$mice and control littermates (Figure 2, H and I).

Hepatic steatosis without metabolic abnormalities in L-Jak2 $2^{-1-}$ Apo $E^{-1-}$ mice. Profound fatty liver in these hepatic Jak2-deficient mice was not accompanied by the usually associated glucose intolerance (Figure 3A). In fact, $L-J a k 2^{-1-} A p o E^{-/-}$mice had improved glucose tolerance compared with control littermates (Figure 3A), similar to our observation in $L-J a k 2^{-/-}$mice (23). Also similar to $L-J a k 2^{-/-}$mice, $L-J a k 2^{-/-} A p o E^{-1-}$ 
mice did not have insulin resistance that usually occurs with fatty liver, as evidenced by comparable glucose lowering during insulin tolerance tests and similar fasting insulin levels compared with control littermates (Figure 3, B and C). Random blood glucose levels were also similar to control littermates (Figure 3D).

We next assessed lipid profiles in these mice to delineate potential mechanisms that may account for the accelerated atherosclerosis in hepatic Jak2-deficient mice. Analysis of plasma lipids revealed no significant differences in the levels of total serum TG or cholesterol (Figure 3, E and F). Fast protein liquid chromatography (FPLC) analysis of serum also revealed no significant differences in VLDL, LDL, and HDL cholesterol between $L-J a k 2^{-1-} A p o E^{-/-}$mice and control littermates (Figure 3, G-J).

$L-J a k 2^{-1-} \mathrm{Ldlr}^{-1-}$ mice also exhibit increased atherosclerosis. To further confirm the atheroprotective effect of hepatic Jak2, we used another atherosclerosis-prone model with LDL receptor deficiency by generating Alb-Cre ${ }^{+} J a k 2^{f l f l} L d l r^{--}$mice, referred to herein as $L-J a k 2^{-1-} L d l r^{--}$, and $A l b-C r e^{+} J a k 2^{+/+} \mathrm{Ldlr}^{--}$control littermates, referred to herein as $L-J a k 2^{+/+} L d l r^{-/}$, and placed them on an atherogenic diet for 12 weeks. These $L-J a k 2^{-/-} L d$ $\mathrm{lr}^{-/}$mice also showed an increase in atherosclerotic plaque burden compared with control littermates, similar to results seen in the ApoE-deficient model, as determined by both en face assessment of the descending aorta (Figure 4A) and lesion area in the longitudinal section of the lesser curvature of the aortic arch (Figure 4B). Similarly, $L-J a k 2^{-1-} L d l r^{--}$mice had profoundly increased macrophage content (Figure 4C) and decreased plaque smooth muscle cell content within atheromas compared with control littermates (Figure 4D). Furthermore, $L-J a k 2^{-1-} L d l r^{--}$mice, similar to $L-J a k 2^{-1-} A p o E^{-/}$mice, exhibited profound hepatic steatosis without metabolic disturbances such as glucose intolerance, insulin resistance, or systemic inflammation, as measured by serum cytokines or leukocytes (Figure $5, \mathrm{~A}-\mathrm{K}$ ). While total serum cholesterol levels were not significantly

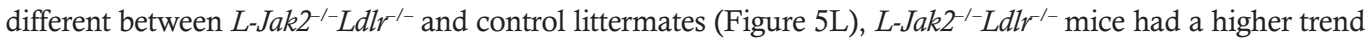
in total serum TG (Figure 5M) and VLDL cholesterol levels compared with littermate controls, which often associate with fatty liver, without differences in LDL or HDL cholesterol levels (Figure 5, N-Q).

Causal role of low-circulating IGF-1 in the accelerated atherosclerosis of L-Jak2 ${ }^{-1-}$ ApoE $E^{-1-}$ mice. We and others have shown hepatic Jak2 to be an essential signaling partner to growth hormone receptor (GHR) that is required for the activation of STAT5 $(22,23)$. Activation of the GHR/JAK2 pathway leads to the transcription of Igf1, a STAT5 target gene that is the major contributor to circulating IGF-1 (36, 37). As such, L-Jak2 $2^{--} \mathrm{ApoE}^{-/-}$mice showed significantly decreased expression of phosphorylated STAT5 in the liver (Figure 6A). Phosphorylation of STAT3, another signaling partner of JAK2 that has been shown to respond to cytokines such as IL-6 and leptin $(38,39)$, was not changed with hepatic Jak2 deficiency (Figure 6A). The residual expression of JAK2 likely reflects JAK2 expression in nonhepatocytes, such as stellate cells, Kupffer cells, and sinusoidal endothelial cells. In accordance with the essential role of hepatic JAK2 in GH signaling, $L-J a k 2^{-1-} A p o E^{-1-}$ mice showed a marked decrease in hepatic expression of Igf1 (Figure 6B) and a reduction in serum IGF-1, in support of the liver being the major source of this hormone in circulation (Figure 6C). L-Jak2 $2^{-1-} L d l r^{-1}$ mice similarly showed a marked reduction in levels of serum IGF-1 (Figure 6D). As one would expect, no significant differences in the mRNA expression of Jak2 or Igf1 were observed in the vasculature of $L-J a k 2^{-1-} L d l r^{--}$mice compared with control littermates (Supplemental Figure 2, A and B). Additionally, both $L-J a k 2^{--} A p o E^{-/-}$and $L-J a k 2^{-1-} L d l r^{--}$mice had increased levels of serum GH, reflecting reduced feedback inhibition at the level of the hypothalamus (Figure 6, E and F).

To test whether the low-circulating IGF-1 in hepatic Jak2-deficient mice may have a causal role in their accelerated atherosclerosis, we infused an IGF-1 analog using osmotic minipumps to continuously provide circulating hormone levels for the duration of atherogenic diet feeding. Long arginine 3-IGF-1 (LR3 IGF-1) is an analog with a substitution of amino acid arginine (Arg) for glutamic acid (Glu) at position 3 of IGF-1 with an extended N-terminal tail leading to superior potency due to decreased affinity for IGF binding proteins. We used $1 \mathrm{mg} / \mathrm{kg} /$ day (d) of LR3 IGF-1, a dose previously shown to effectively restore the GH-IGF1 axis in a mouse model deficient in this axis (40). In support of LR3 IGF-1 infusion sufficiently restoring the somatotroph axis function, the elevated $\mathrm{GH}$ levels in $L-J a k 2^{-1-} \mathrm{ApoE}^{-/-}$mice reversed to similar levels as those of $L-J_{a k 2}{ }^{+/+} \mathrm{ApoE}^{-/-}$mice after LR3 IGF-1 infusion (Figure 7A). These results suggest that the infusion led to restoration of circulating IGF-1 to physiologic levels.

Intriguingly, $L-J a k 2^{-1-} A p o E^{-/-}$mice with LR3 IGF-1 infusion had a significant attenuation in atherosclerotic plaque burden in their descending aorta compared with vehicle-infused $L-J a k 2^{-1-} A p o E^{-/-}$mice, reaching similar levels to $L-J a k 2^{+/+} A p o E^{-/-}$controls (Figure 7B), in support of IGF-1's role in atheroprotection other features of accelerated atherosclerosis, including less necrotic core and decreased atherosclerotic lesion area in longitudinal sections of the lesser curvature of the aortic arch (Figure 7C). Furthermore, 
A

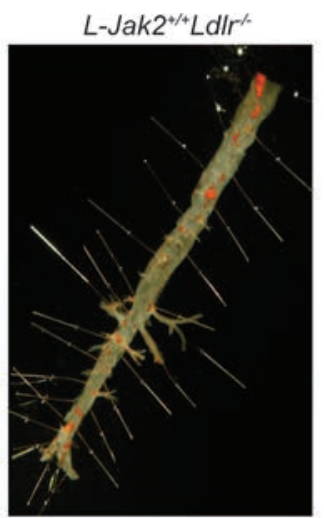

B

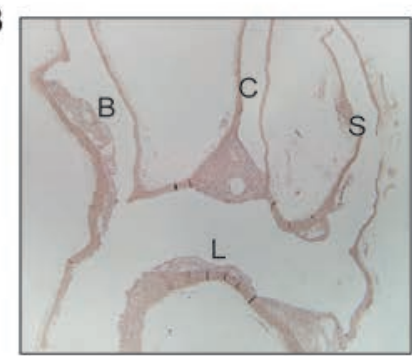

C

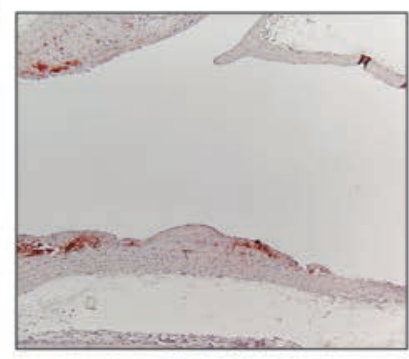

D

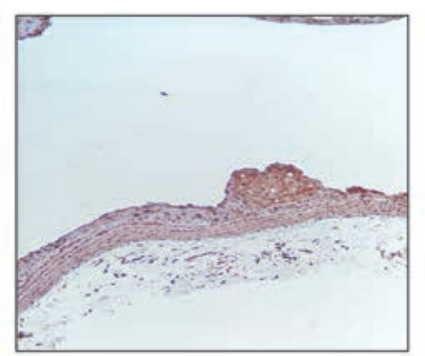

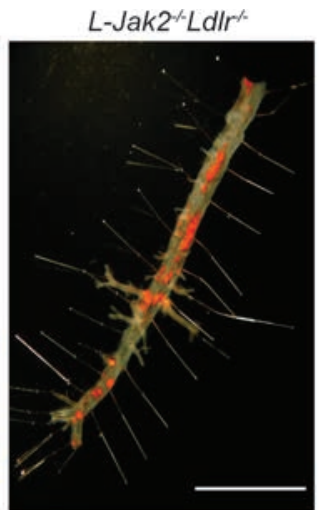
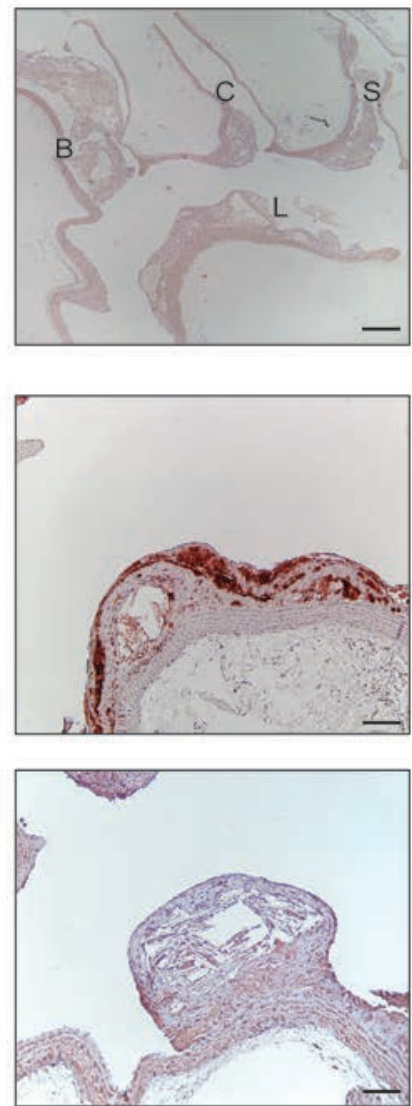
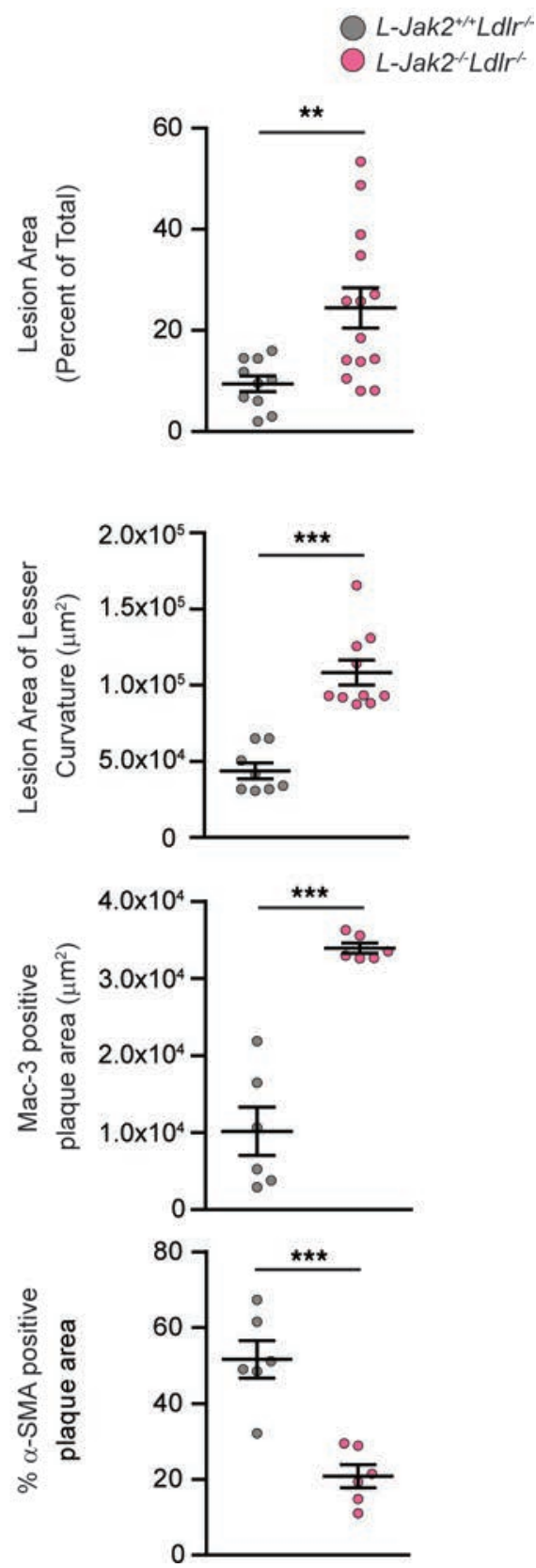

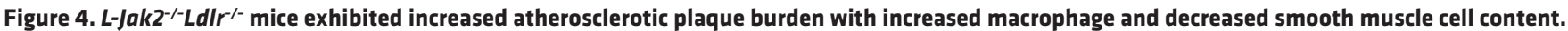
Ldlr-null mice with hepatic Jak2 deficiency ( $\left.L-J a k 2^{-1-} L d l r^{-1-}\right)$ and littermate controls $\left(L-J a k 2^{+/+} L d l r^{-1}\right)$ were fed an atherogenic diet containing $1.25 \%$ cholesterol for 12 weeks, starting at 6 weeks of age. (A) Representative photographs of en face oil red 0 (ORO) staining and quantification of atherosclerotic plaque

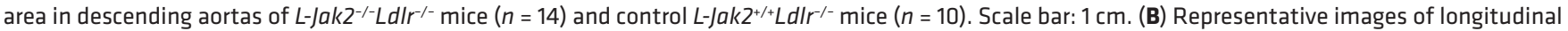
sections from the aortic arch of $L-J a k 2^{-1-L d l r^{-1-}}$ mice $(n=10)$ and control $L-J a k 2^{+/+} L d l r^{-/-}$mice $(n=8)$ stained with H\&E and quantification of lesion size at the lesser curvature. B, brachiocephalic artery; C, left common carotid; S, subclavian artery; L, lesser curvature. Scale bar: $200 \mu \mathrm{m}$. (C and D) Representative

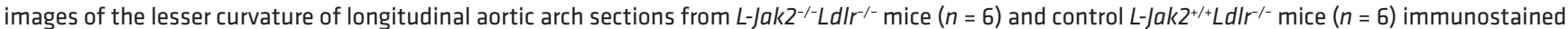
with antibody against Mac- 3 and $\alpha$-smooth muscle actin ( $\alpha-S M A)$ and quantification of positively stained area expressed as an absolute number or percentage. Scale bars: $100 \mu \mathrm{m}$. In each of the panels, each dot in the scatter plot indicates an individual animal. Data represent mean \pm SEM. Differences between groups were analyzed for statistical significance by Student unpaired $t$ test. ${ }^{* *} P<0.01,{ }^{* *} P<0.001$.

decreased macrophage content within the atherosclerotic plaques of IGF-1-infused $L-J a k 2^{-1-} A p o E^{-1-}$ mice was observed compared with vehicle-infused $L-J a k 2^{-1-A p o E^{--}}$mice (Figure 7D). LR3 IGF-1 infusion at the concentrations we used had no significant effect on atherosclerotic plaque burden and lesion area in $L-J a k 2^{+/+} A p o E^{-/-}$mice (Figure 7, B and C), likely due to the lack of advanced lesions that is required to detect the reduction that may be mediated by LR3 IGF-1 in the examined timeframe. LR3 IGF-1 infusion 
A

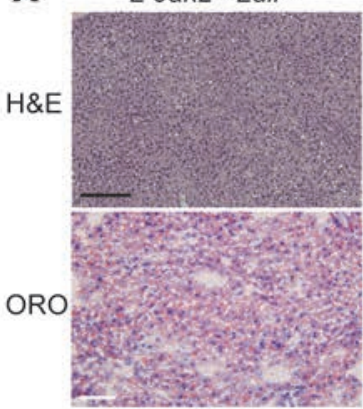

L-Jak2 Ld IIr

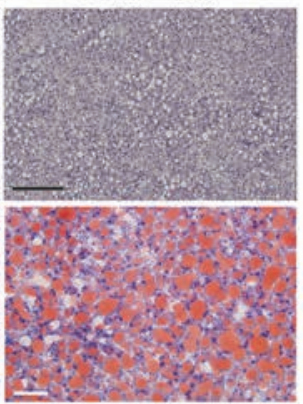

B

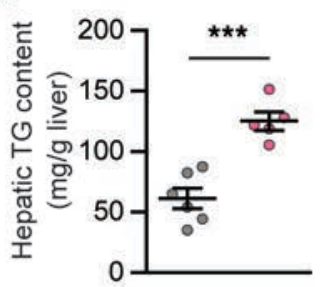

L-Jak2 ${ }^{* /+} L d I r^{\prime}$

L-Jak2 ${ }^{\prime-L d I r}$

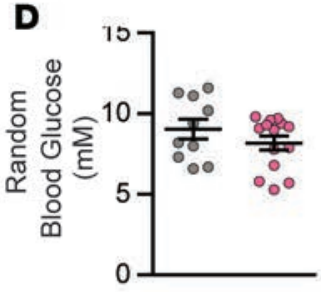

E

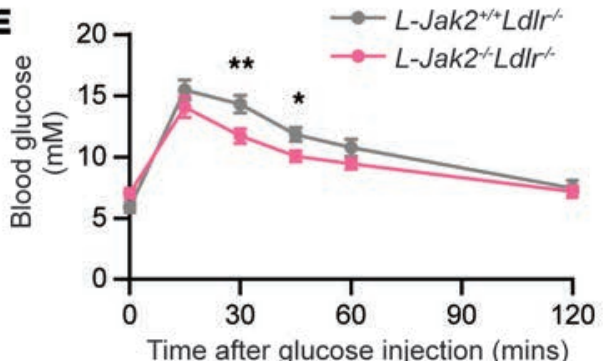

C

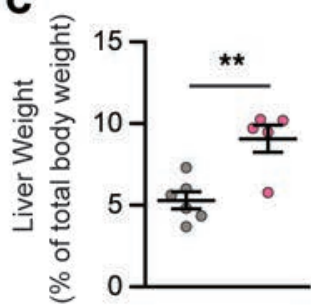

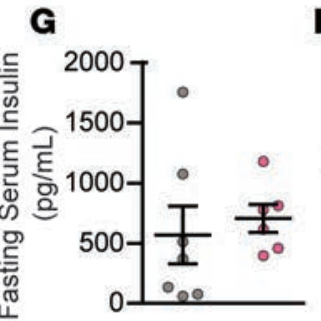

H

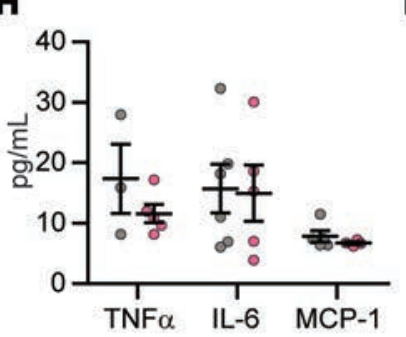

I

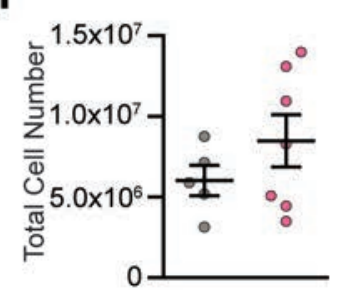

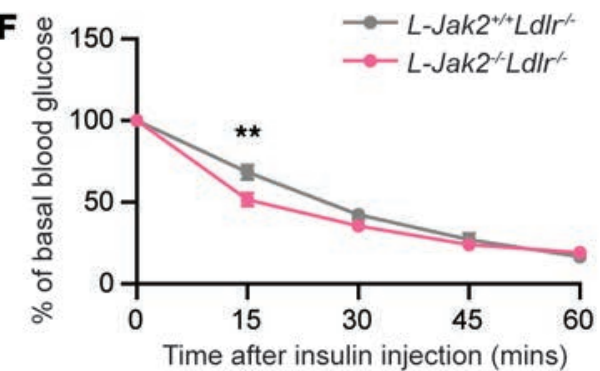

J

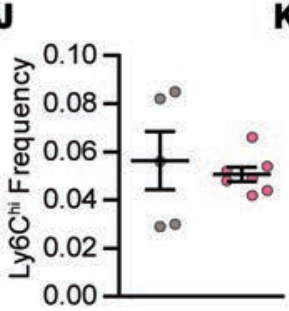

K
$\mathbf{L}$

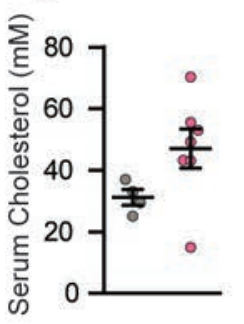

M

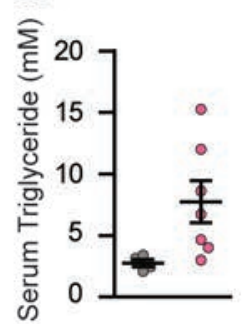

N

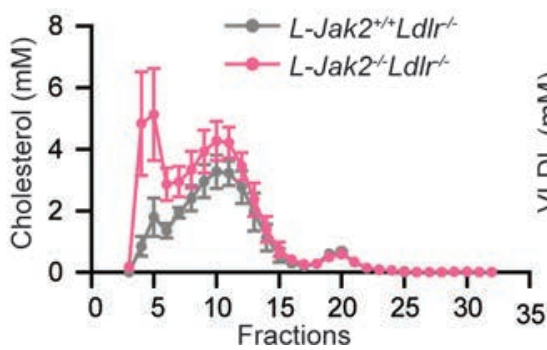

○

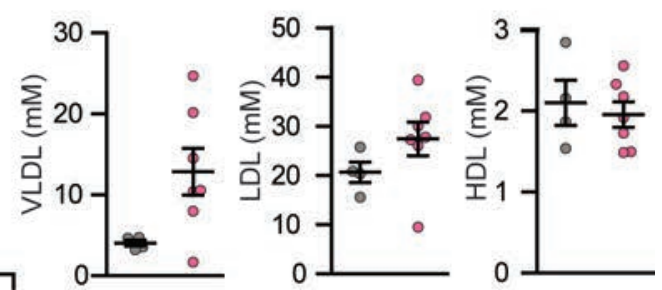

Figure 5. L-Jak2-/-LdIr/- mice develop profound hepatic steatosis but do not display glucose intolerance, insulin resistance, or systemic inflammation.

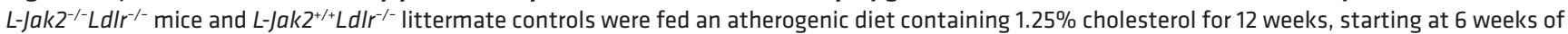

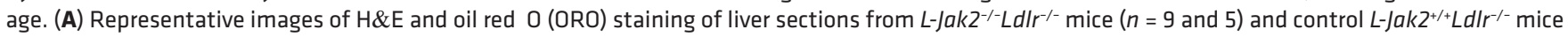

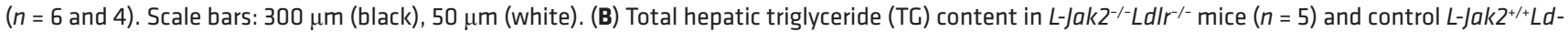

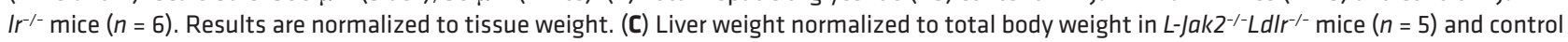

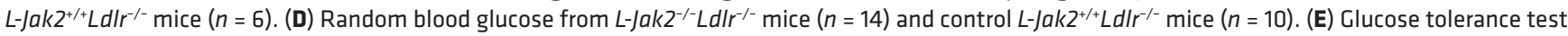
in overnight-fasted $L-J a k 2^{-/-} L d l r^{-/-}$mice $(n=15)$ and control $L-J a k Z^{+/+} L d l r^{-/-}$mice $(n=11)$. Mice received glucose $(1 \mathrm{~g} / \mathrm{kg})$ i.p., and blood glucose was measured

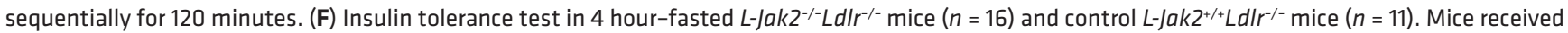
insulin ( 0.75 units $/ \mathrm{kg}$ ) i.p., and blood glucose was measured sequentially for 60 minutes. Data are expressed as a percentage of basal (fasting) glucose.

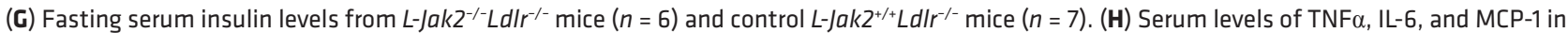

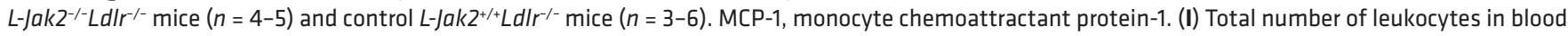

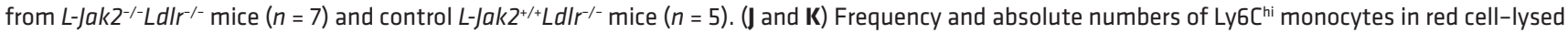
blood from $L-J a k 2^{-1-L d l r^{-1-}}$ mice $(n=7)$ and control $L-J a k 2^{+/+} L d l r^{-1-}$ mice $(n=5)$ using flow cytometry. Ly $6 C^{\text {hi }}$ monocytes were defined based on CD115+Ly6ChiLy6G- expression. Total serum (L) cholesterol; $P=0.1061$ and $(\mathbf{M})$ triglycerides from $L-J a k 2^{-/-} L d l r^{-/-}$mice $(n=7)$ and control $L-J a k Z^{+/+} L d l r^{-/-}$mice $(n=4)$. ( $\left.\mathbf{N}-\mathbf{Q}\right)$ Distribution of serum cholesterol among lipoprotein fractions determined by fast performance liquid chromatography (FPLC) and total serum VLDL, LDL,

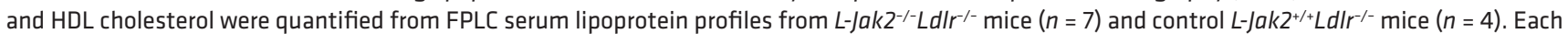
dot in scatter plots indicate an individual animal. Data represent mean \pm SEM. Differences between groups were analyzed for statistical significance by Student unpaired $t$ test. ${ }^{*} P<0.05,{ }^{*} P<0.01,{ }^{* *} P<0.001$. 

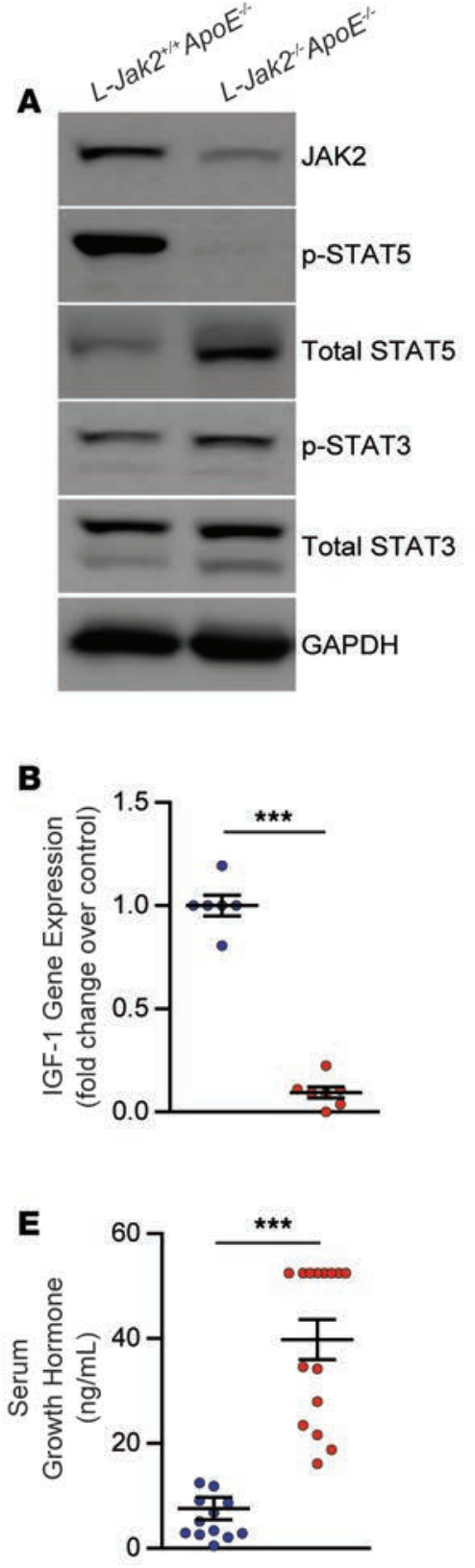

L-Jak2 ${ }^{+/ 4} A p o E^{-1}$

$L-J a k 2^{-A p o E^{-}}$
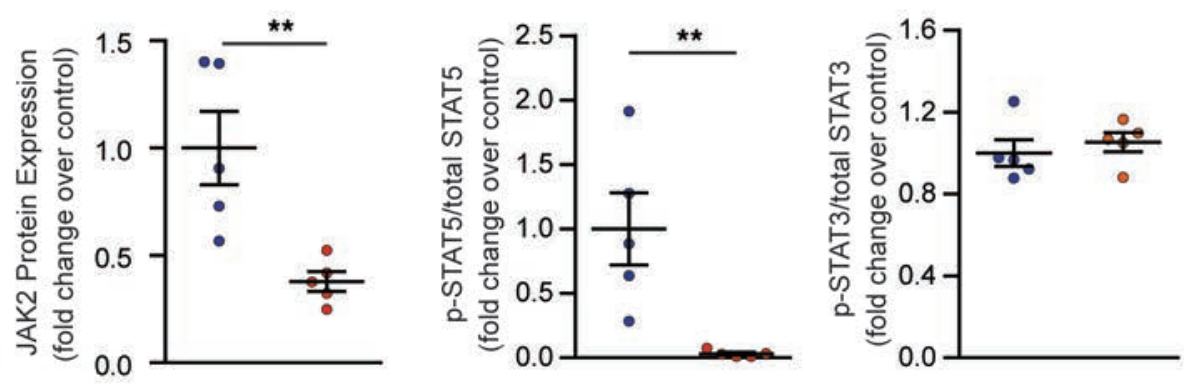
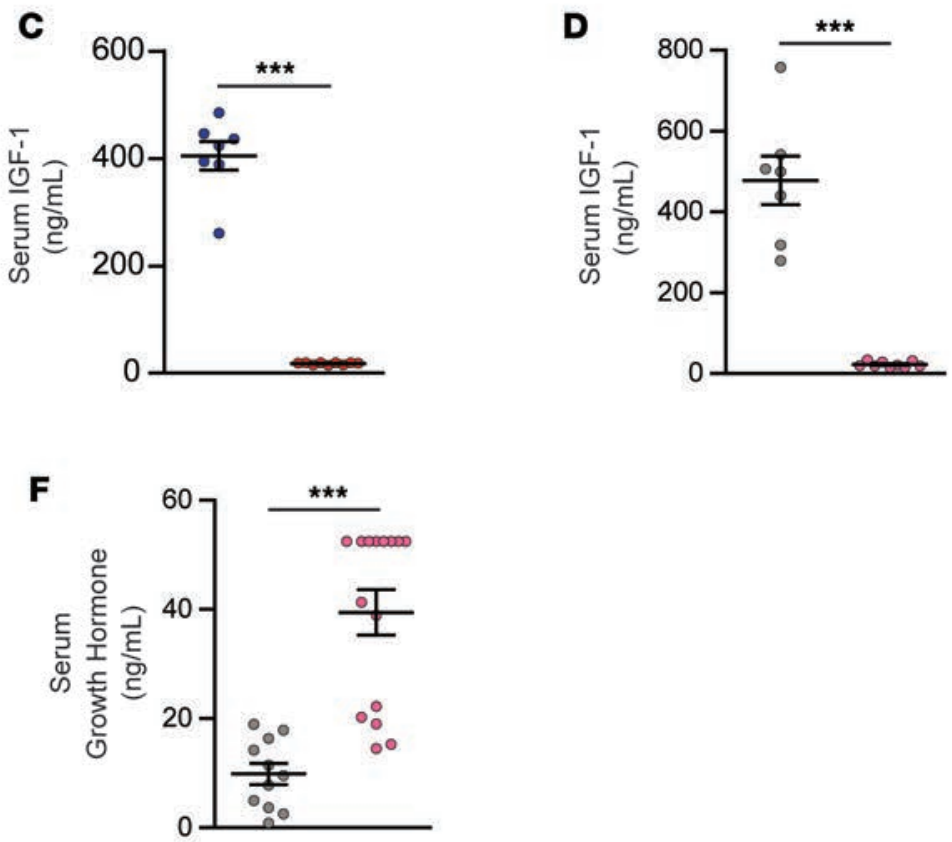

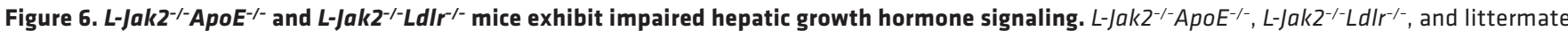
controls ( $L-J a k 2^{+/+} \mathrm{ApoE}^{-/-}$or $\mathrm{L}-J a k 2^{+++} \mathrm{Ldll}^{-/-}$, respectively) were fed an atherogenic diet containing either $0.2 \%$ cholesterol (for ApoE-null mice) or $1.25 \%$ cholesterol (for Ldlr-null mice) for 12 weeks, starting at 6 weeks of age. (A) Western blots and quantitative summary of JAK2, phospho-STAT5, total STAT5, phospho-STAT3, and total STAT3 in liver homogenates from $L-J a k 2^{-/-} A p o E^{-/-}$mice $(n=5)$ and control $L-J a k 2^{+/+} A p o E^{-/-}$mice $(n=5)$. Protein band intensity was quantified by Imagel software, and levels of JAK2 were normalized to expression of GAPDH; levels of p-STAT5 and p-STAT3 were normalized first to expression of GAPDH and then normalized to expression of total STAT5 and STAT3, respectively. Values are presented as fold change

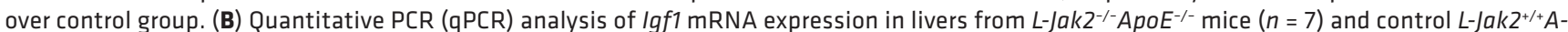
poE $E^{-/-}$mice $(n=6)$. Values are normalized to 185 mRNA levels and presented as fold change over control group. (C) Serum levels of IGF-1 measured

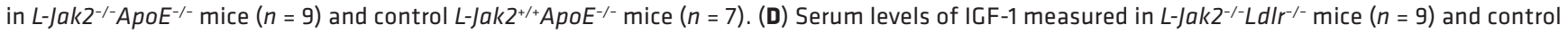
$L-J a k 2^{+/+} L_{d l l} r^{-1}$ mice $(n=7)$. (E) Serum levels of growth hormone $(\mathrm{GH})$ measured in $L-J a k 2^{-/-} A p o E^{-/-}$mice $(n=15)$ and control $L-J a k 2^{+/+} A p o E^{-/-}$mice $(n=$ 12). (F) Serum levels of GH measured in $L-J a k 2^{-/-} L d l r^{-/-}$mice $(n=15)$ and control $L-J a k 2^{+/+} L d l r^{-/-}$mice $(n=11)$. In each of the panels, each dot in the scatter plot indicates an individual animal. Data represent mean \pm SEM. Differences between groups were analyzed for statistical significance by Student unpaired $t$ test. ${ }^{* *} P<0.01,{ }^{* *} P<0.001$. 
A
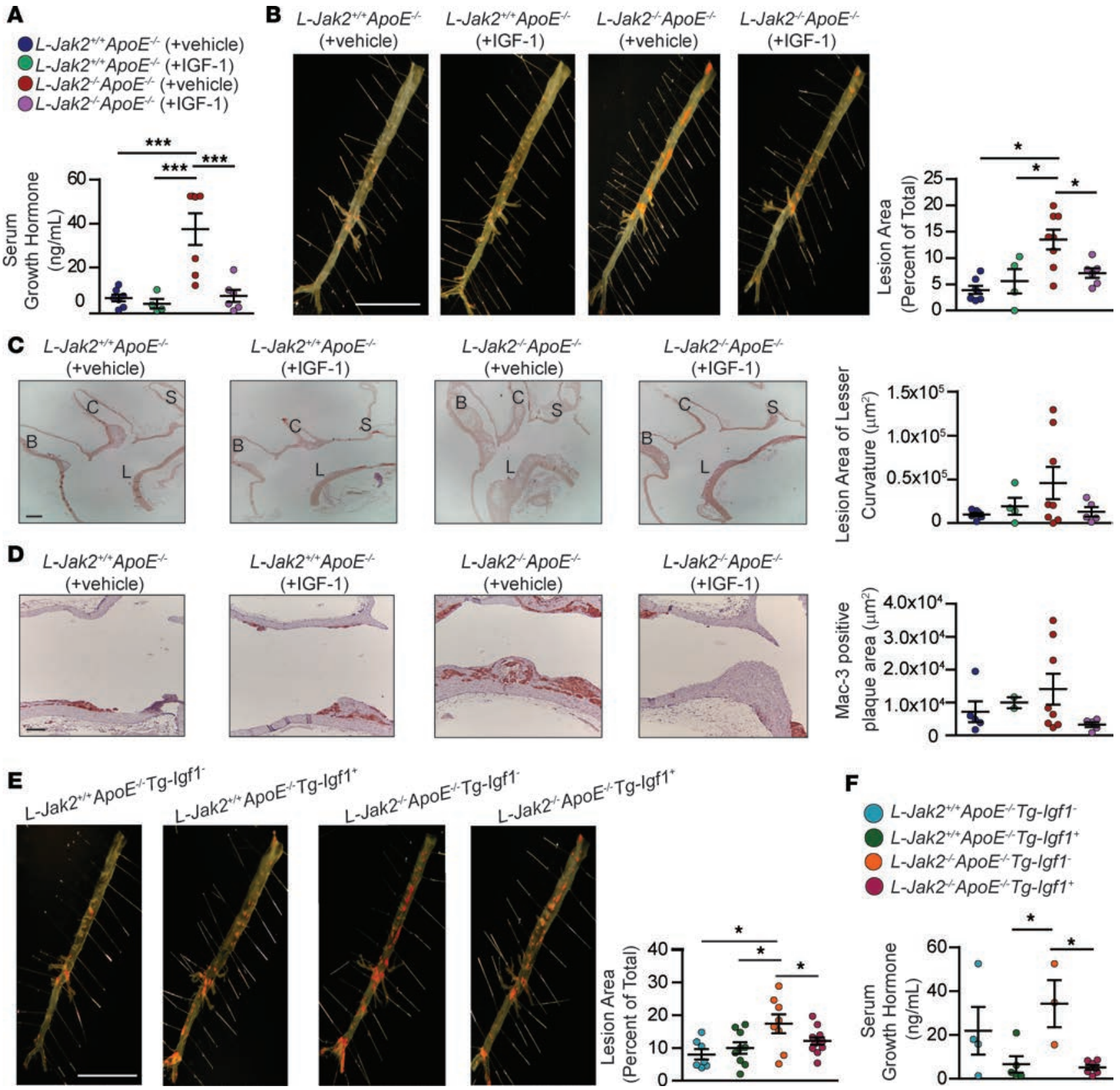

\section{L-Jak2 ApoE}
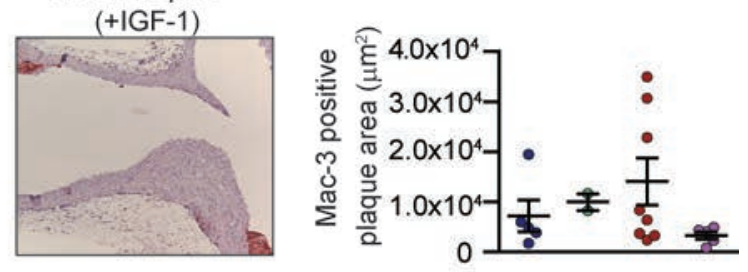

$\mathbf{F}$
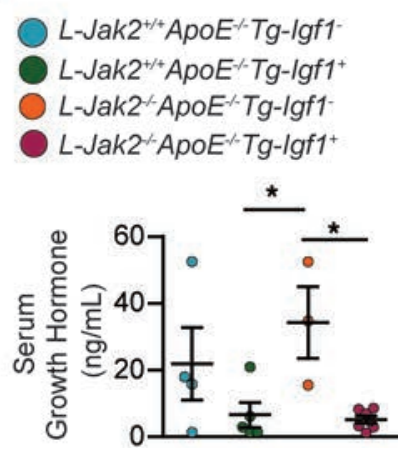

Figure 7. Restoration of IGF-1 reduces circulating growth hormone levels and attenuates atherosclerotic plaque burden in L-Jak2 $\mathbf{2}^{-/-} \mathrm{ApoE^{-/- }}$ mice. To restore circulating IGF-1 levels by pharmacologic means, vehicle (saline $+10 \mathrm{mmol} / \mathrm{L} \mathrm{HCl}$ ) or human long R3 IGF-1 (1.0 mg $/ \mathrm{kg} / \mathrm{d}$ ), a biologically active IGF-1 analog, was

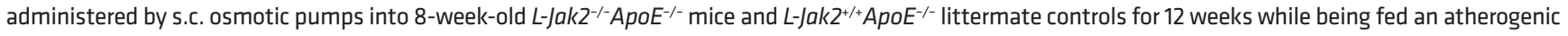
diet containing $0.2 \%$ cholesterol. (A) Serum growth hormone (GH) levels were measured in vehicle-infused $L_{-} J a k 2^{+/+} A p o E^{-/-}(n=7)$, IGF-1-infused $L_{-j a k 2^{++} A-}$

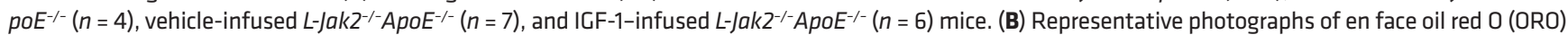
staining and quantification of atherosclerotic plaque area in descending aortas of vehicle-infused $L-J a k Z^{+++} A p o E^{-/-}(n=7)$, IGF-1-infused $L-J a k Z^{+/+} A p o E^{-/-}(n=$

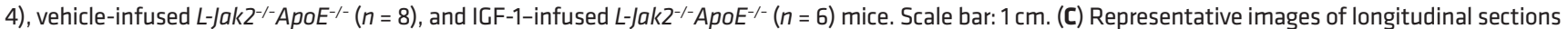
from the aortic arch of vehicle-infused $L-J a k 2^{+++} A p o E^{-/-}(n=6)$, IGF-1-infused $L-J a k Z^{++} A p o E^{-/-}(n=4)$, vehicle-infused $L-J a k 2^{-/-} A p o E^{-/-}(n=8)$, and IGF-1-infused L-Jak2 ${ }^{-1-} A p o E^{---}(n=5)$ mice stained with H\&E and quantification of lesion size at the lesser curvature. B, brachiocephalic artery; C, left common carotid; S, subclavian artery; L, lesser curvature. Scale bar: $200 \mu \mathrm{m}$. (D) Representative images of the lesser curvature of longitudinal aortic arch sections from vehicle-infused

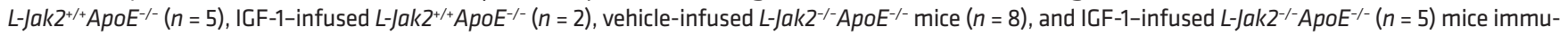
nostained with antibody against Mac-3 and quantification of positively stained area. Scale bar: $100 \mu \mathrm{m}$. To restore circulating ICF-1 using a genetic approach,

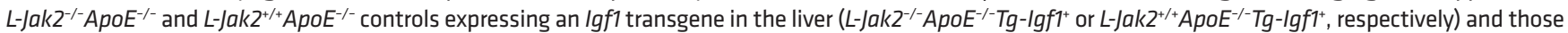
not expressing the transgene ( $L-J a k 2^{-/-} A p o E^{-/-} \mathrm{Tg}-\mathrm{Igf1} 1^{-}$or $\mathrm{L}^{-J a k 2^{+/}} \mathrm{ApoE}^{-/-} \mathrm{Tg}-\mathrm{Igf1}$, respectively) were fed an atherogenic diet containing $0.2 \%$ cholesterol for $13-14$ weeks, starting at 8 weeks of age. (E) Representative photographs of en face ORO staining and quantification of atherosclerotic plaque area in descending aor-

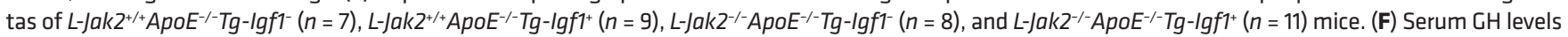

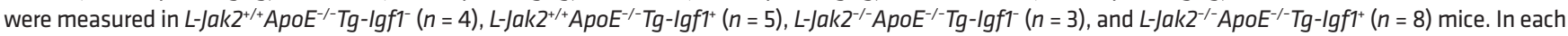
of the panels, each dot in the scatter plot indicates an individual animal. Data represent mean \pm SEM. Differences between groups were analyzed for statistical significance using One-way ANOVA with Newman-Keuls post-hoc test. ${ }^{*} P<0.05,{ }^{* *} P<0.001$. 
did not affect glucose tolerance, insulin sensitivity, or total serum cholesterol or TG levels significantly in L-Jak2 $2^{-1-} \mathrm{ApoE}^{-1-}$ or control mice (Supplemental Figure 3, A-D). Interestingly, in addition to the atheroprotective effects of LR3 IGF-1 infusion in $L-J a k 2^{-1-} A p o E^{-/-}$mice, we observed a visible reduction in fatty liver compared with vehicle-infused $L-J a k 2^{-1-} A p o E^{-/-}$mice by H\&E and ORO staining (Supplemental Figure $3 \mathrm{E}$ ), along with reduced liver TG content compared with control littermates (Supplemental Figure $3 \mathrm{~F}$ ).

In addition to restoring circulating IGF-I levels by pharmacologic means, we took a genetic approach by overexpressing Igf1 transgene in the liver (41) of $L-J a k 2^{-/} \mathrm{ApoE}^{-/-}$mice. This also led to a remarkable attenuation of atherosclerotic plaque burden (Figure 7E), while sufficiently suppressing their elevated GH levels to levels comparable with $L-J a k 2^{+/+} \mathrm{ApoE}^{-/-}$mice (Figure 7F). These results further confirm the atheroprotective role of IGF-1 in the setting of hepatic Jak2 disruption. Similar to IGF-1 infusion, overexpression of the IgfI transgene in $L-J a k 2^{-1-} \mathrm{ApoE}^{-/-}$mice did not lead to any significant changes in glucose tolerance or insulin sensitivity (Supplemental Figure 4, A and B). Taken together, these data highlight the pivotal role of low-circulating IGF-1 in the accelerated atherosclerosis in hepatic Jak2-deficient mice, providing a mechanistic link between liver dysfunction that occurs with hepatic Jak2 disruption and increased atherosclerosis.

\section{Discussion}

In this study, we investigated the role of hepatic Jak2, a key mediator of cytokine signaling, in atherogenesis. Using mice with hepatic Jak2 deletion, we show that Jak2 is essential for GH signaling, which results in dramatically reduced circulating IGF-1, and this is associated with accelerated atherosclerotic plaque development. To test whether reduced IGF-1 had a causal role in the accelerated atherosclerosis, we restored IGF-1 levels by pharmacological or genetic means, and both of these strategies attenuated the atherosclerotic burden in hepatic Jak2-deficient mice. Importantly, atherosclerosis in both $L-J a k 2^{-1-} A p o E^{-/-}$and $L-J a k 2^{-1-} \mathrm{Ldlr}^{-1-}$ models occurred without other confounding cardiovascular risk factors, including insulin resistance, glucose intolerance, or systemic inflammation. Together, these data show that hepatic Jak2 is required for $\mathrm{GH}$ signaling that mediates atheroprotection through transcriptional induction of Igf1.

The role of IGF-1 in CVD has been a subject of much interest, prompted by the curious observation in individuals with either high or low levels of IGF-1 such as in acromegaly or hypopituitarism, respectively, that have an increased CVD risk and related mortality. Human studies examining the association of IGF-1 levels with CVD risk remain inconclusive. Depending on the level of circulating IGF-1, different clinical studies have shown IGF-1 to be either a protective or an aggravating factor for CVD. Some prospective and cross-sectional studies show that higher serum levels of IGF-1 are related to increased carotid artery intima-media thickness that increases susceptibility to coronary artery disease and cardiovascular mortality (42-44). Conversely, other studies have shown that lower serum IGF-1 is associated with an increased risk of ischemic heart disease, as well as increased incidence of coronary calcification and carotid atherosclerotic plaques (45-50). There have also been meta-analyses and other studies including a recent prospective study in elderly men that show a U-shaped association between serum IGF-1 levels and cardiovascular events or all-cause mortality $(51,52)$. These varying results likely reflect the complexity of IGF-1 effects on the vasculature that are dependent on a multitude of factors, including the predominant cell type within the atheroma to which IGF-1 targets or the degree of disease progression when IGF-1 effects were examined.

In our study, we have a unique mouse model with hepatic Jak2 deficiency that shows a significant reduction in liver-derived IgfI in which the effect on atherogenesis was examined. Of note, this was accompanied by isolated fatty liver disease without other metabolic abnormalities such as diabetes, insulin resistance, hypercholesterolemia, or systemic inflammation. We demonstrate that low IGF-1 with hepatic Jak2 deficiency played a causal role in accelerating atherosclerosis, as this was attenuated with restoration of circulating IGF-1. Our results show that Jak2 is essential for hepatic GH signaling and support studies showing the detrimental role of IGF-1 deficiency in atherosclerosis. For example, a 20\% reduction in circulating IGF-1 that was found in a congenic 6T/APOE-KO mouse strain was reported to exhibit significantly increased atherosclerotic plaque burden following 12 weeks of Western diet (53). Another study reported that adult-onset IgfI deficiency in C57BL/6 mice results in increased diet-induced fatty streak formation in female mice (54). Furthermore, administration of IGF-1 by systemic infusions in ApoE-null mice at a pharmacological dose of $1.5 \mathrm{mg} / \mathrm{kg} / \mathrm{d}$ showed a reduction in atherosclerotic plaque burden (55). Some possible mechanisms by which IGF-1 infusion reverses the accelerated atherosclerosis include its effect on cholesterol efflux, given a recent study linking IGF-1 and HDL cholesterol (56). 
While the somatotroph axis appears to be the primary pathway affected by hepatic Jak2 disruption (22, 23), with accelerated atherosclerosis being attenuated with restoration of this axis, we cannot rule out other hepatic Jak2-mediated signalling pathways contributing to accelerated atherosclerosis. JAK2 functions at the junction of many biological processes by mediating a variety of cytokines and growth factors in multiple cell types, including IL-6, IL-12, macrophage CSF, ciliary neurotrophic factor, oncostatin M, IFN- $\gamma$, GH, prolactin, erythropoietin, and leptin $(57,58)$. In vascular smooth muscle cells, JAK2 has been shown to interact with the angiotensin II type 1 receptor in mediating angiotensin II-induced hypertension (19) and neointimal formation (18), both of which have been shown to aggravate atherosclerosis. Despite these many possible mechanisms by which Jak2 deficiency can exacerbate atherosclerosis, our results show that reduced circulating IGF-1 is primarily responsible for accelerated atherosclerosis that was observed in Jak2-deficient mice, and restoring IGF-1 levels was sufficient to attenuate atherosclerotic plaque burden. Indeed, our data illustrate a link between the liver and atherosclerosis through the hepatic JAK2/IGF-1 axis. However, given the potential role of GH in atherosclerosis including lipid metabolism (59), an important future study would be to delineate the relative direct contribution of the changes in GH versus IGF-1 in atherosclerosis.

In addition to the systemic IGF-1 infusion attenuating atherosclerotic plaque burden in hepatic Jak2deficient mice potentially through direct actions in the vasculature, we also observed attenuated hepatic steatosis in these mice. Thus, atheroprotection by IGF-1 may also occur through its effects in the liver. Our observation on the effects of IGF-1 on fatty liver is in line with a previous study demonstrating IGF-1 administration to attenuate steatohepatitis and fibrosis present in a GH-deficient rat model (60), as well as another study demonstrating improvement in liver function and a decrease in fibrosis in a rat carbon tetrachloride-induced cirrhosis model following IGF-1 treatment (61). In contrast, another study did not show any effects of IGF-1 infusion on hepatic steatosis that was present in liver-specific Ghr-KO mice, despite restoration of circulating $\mathrm{GH}$ to normal levels (62).

Identifying a definitive mechanistic link between nonalcoholic fatty liver disease (NAFLD) and CVD is challenging due to multiple concurrent metabolic abnormalities, including insulin resistance and type 2 diabetes that cosegregate with NAFLD. However, in our model of hepatic Jak2-deficient mice, NAFLD is present without the usually associated metabolic defects. Thus, we have a unique model of isolated NAFLD in which we can study its effects on atherosclerosis and identify a novel IGF-1-mediated connection between NAFLD and atherosclerosis. Indeed, individuals with NAFLD have a 10\%-30\% reduction in circulating IGF-1 levels compared with controls, and IGF-1 concentrations have been shown to inversely correlate with severity of nonalcoholic steatohepatitis (NASH) $(63,64)$. This inverse relationship between IGF-1 and NAFLD is also seen in obese children and adolescents (65). Thus, IGF-1 may serve as a mechanistic link between fatty liver and atherosclerosis.

Besides JAK2, other upstream regulators of hepatic IGF-1 may mediate its effects, such as FGF21, PPAR $\gamma$, and components of the hedgehog signaling pathway including Smoothened (66-68). Furthermore, recent clinical studies have shown $\omega-3$ supplementation and baclofen, a $\beta$-p-chlorophenyl derivative of $\gamma$-aminobutyric acid (GABA), in increasing plasma IGF-1 concentrations to varying extent (69-71).

In our current study, we show that Jak2 is essential in GH signaling in liver and that low Igf1 in L-Jak2-1$A p o E^{-/-}$mice plays a causal role in the accelerated atherosclerosis. As such, restoration of IGF-1 either with continuous infusion or with genetic overexpression attenuated the accelerated atherosclerosis in $L-J a k 2^{-1}$ $A p o E^{-1-}$ mice. Together, we uncovered a mechanistic link between NAFLD and atherosclerosis through hepatic Jak2-dependent production of IGF-1 that provides atheroprotection. We highlight a liver-centric mechanism by which atherosclerosis occurs as a therapeutic strategy for the treatment of CVD.

\section{Methods}

Generation of ApoE-null or Ldlr-null hepatocyte-specific Jak2-KO mice. Hepatocyte-specific Jak2-KO mice, $A l b-C r e^{+} J A K 2^{f l f l}$, were previously generated as described (23). To generate ApoE-null hepatic Jak2-deficient mice, Alb-Cre $J A K 2^{f l f l}$ were crossed to $A p o E^{-/-}$mice (The Jackson Laboratory, B6.129P2-Apoetm1Unc/J; stock number 002052) resulting in $\mathrm{Alb}-\mathrm{Cre}^{+} \mathrm{Jak2}^{+/ f t} \mathrm{ApoE}^{+/-}$mice. These mice were intercrossed to generate $L-J a k 2^{-1-} A p o E^{-/-}$and $L-J a k 2^{+/+} A p o E^{-/-}$, which were used as littermate controls. Similarly, Ldlr-null hepatic Jak2-deficient mice were generated by crossing $A l b-C r e^{+} J A K 2^{f l / f l}$ mice to $L d l r^{-1}$ mice (The Jackson Laboratory, B6.129S7-Ldlrtm1Her/J; stock number 002207) with similar strategies as used to generate $A p o E$ null mice as described. Mice were maintained on a mixed C57BL/6 and 129/Sv background. Mice were housed in a temperature-controlled pathogen-free animal facility with a 12-hour light and dark cycle with free access to water and food. Only male mice were used for experiments and were fed a standard rodent 
chow diet (5\% fat; Harlan Teklad) until 6 weeks of age followed by an atherogenic diet containing $0.2 \%$ cholesterol for the $A p o E^{-1-}$ model (TD88137, Harlan Laboratories) or $1.25 \%$ cholesterol for the $\mathrm{Ldlr}^{-/-}$model (D12108; Research Diets Inc.) for 12 weeks. Another cohort of $L-J a k 2^{-1-} \mathrm{ApoE}^{-/-}$and littermate control $L-J a k 2^{+/+} A p o E^{-/-}$mice were fed a standard rodent chow diet for 22 weeks.

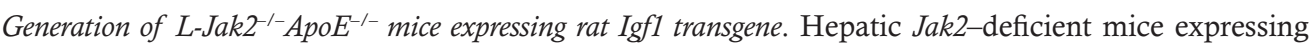
the hepatic rat IgfI transgene (referred to herein as $L-J a k 2^{-1-} A p o E^{-1-} \mathrm{Tg}-\mathrm{Ig} f 1^{+}$) were generated by crossing $L-J a k 2^{-1-} A p o E^{-/-}$mice with hepatic Igf1 transgenic mice. Hepatic Igfl transgenic mice, referred to herein as $T g$-Igf1 ${ }^{+}$(The Jackson Laboratory, FVB-Tg(Ttr-Igf1)1Sykr/J; stock number 012662), overexpress rat Igf1 specifically in the liver under the control of the rat transthyretin promoter (41). The resulting $\mathrm{Alb}-\mathrm{Cre} \mathrm{Jak2}^{+\prime}$ ${ }^{f l} \mathrm{ApoE}^{+/} \mathrm{Ig} \mathrm{II}^{+/-}$mice were intercrossed to generate ApoE-null mice expressing the Cre recombinase with or without loxP-flanked Jak2 alleles and with or without Igf1 transgene. Hemizygous and homozygous transgenic animals exhibit the same phenotype and cannot be distinguished by standard polymerase chain reaction (41). Male mice were used for experiments, and these mice were maintained on a mixed C57BL/6, $129 / \mathrm{Sv}$, and FVB/NJ background. Mice were fed a standard rodent chow diet (5\% fat; Harlan Teklad) until 8 weeks of age, after which an atherogenic diet containing $0.2 \%$ cholesterol (TD88137, Harlan Laboratories) was provided for an additional 13-14 weeks.

Atherosclerosis assessment and quantification. Atherosclerotic plaque burden in the descending aorta was assessed distal to the left subclavian artery to the iliac bifurcation as previously described (72). Under anesthesia, the entire arterial tree was perfused with PBS ( $\mathrm{pH} 7.3$ ) for 2 minutes followed by $4 \%$ paraformaldehyde in 0.1 M PBS ( $\mathrm{pH}$ 7.4) for 10 minutes. The full length of the aorta, which included the aortic arch to the iliac bifurcation, was dissected out. The descending aorta was severed from the aortic arch and then opened longitudinally, pinned en face and stained with ORO as previously described (73). Stained aortas were imaged using a CoolPix digital camera (Nikon). The extent of lesion development was defined as percentage of ORO-positive plaque area per total aortic surface area and was quantified using ImageScope version 11.0.2.716 software (Aperio Technologies).

Analysis of serum parameters. Blood was collected at sacrifice by cardiac puncture from overnight-fasted mice. Serum insulin, TNF $\alpha$, IL-6, and MCP-1 were measured using a serum adipokine kit (Millipore) by the Luminex 100 Instrumental System. Serum GH and IGF-1 were measured using a mouse GH ELISA kit (Millipore) and mouse/rat IGF-1 ELISA kit (R\&D Systems), respectively, as per the manufacturer's instructions. Serum ALT and AST levels were measured by IDEXX Ltd. (Markham). Serum total cholesterol, TG, and the assessment of lipoprotein distribution by FPLC were performed in the lipid laboratory at St. Michael's Hospital, Ontario, Canada. Serum total cholesterol and TGs for the IGF-1 infusion experiments were determined at the Mouse Metabolic Phenotyping Centre (Vanderbilt University, Nashville, Tennessee, USA; Mouse Metabolic Phenotyping Centre [MMPC], grant DK59637).

Hepatic TG content. Hepatic lipids were extracted, and hepatic TG content was quantified as previously described (74).

Histology and IHC. Liver and aortic arch were fixed in 4\% paraformaldehyde in PBS solution (pH 7.4). Tissue sections were stained with H\&E and imaged by light microscopy (Leica Microsystems Inc.). Atherosclerotic plaque size on the lesser curvature of aortic arches was measured using cellSens software (Olympus). Plaque area was defined as the region extending from the internal elastic lamina to the luminal edge of the plaque. Immunohistochemical analysis was performed on longitudinal aortic arch sections using anti-Mac3 (1:200, M3/84 clone, BD Pharmingen) and anti- $\alpha$-SMA antibody (1:500, A2547, Sigma-Aldrich) with antigen retrieval TRIS-EDTA Buffer (10 mM Tris Base, 1 mM EDTA Solution, 0.05\% Tween 20, pH 9.0). Thresholding of maximum and minimum color intensity was conducted using ImageScope version 11.0.2.716 software (Aperio Technologies) with positively stained regions expressed as an absolute value or percentage of plaque area. For ORO staining, livers were immersed in Tissue-Tek OCT compound (Sakura) and sections were stained with ORO (Sigma-Aldrich) as previously described (75).

Immunoblotting. Immunoblotting of protein lysates was performed as previously described (76). The following antibodies were used: total JAK2 (1:1,000, catalog 3230, Cell Signaling Technology), total STAT5 (1:1,000, catalog 9363, Cell Signaling Technology), phospho-STAT5 (Tyr694) (1:1,000, catalog 4322, Cell Signaling Technology), total STAT3 (1:1,000, catalog 9363, Cell Signaling Technology), phospho-STAT3 (Tyr705) (1:1,000, catalog 9145, Cell Signaling Technology), and GAPDH (1:1,000, catalog 2118, Cell Signaling Technology). Membrane blots were visualized by enhanced chemiluminescence (PerkinElmer Inc.). Signal quantification was obtained using ImageJ software. 
Table 1. Primer sequences for quantitative PCR

\begin{tabular}{|c|c|c|}
\hline Gene & Forward $\left(5^{\prime}-3^{\prime}\right)$ & Reverse $\left(5^{\prime}-3^{\prime}\right)$ \\
\hline $18 s$ & AGTCCСTGCССTTTGTACACA & CGATCCGAGGGCCTCACTA \\
\hline aSma & CCACCGCAAATСCTTCTAAGT & GGCAGGAATGATTTGGAAAGG \\
\hline $\operatorname{lgf1}$ & GGCATTGTGGATGAGTGTTG & TCTCCTTTGCAGCTTCGTTT \\
\hline 116 & СTCTGGGAAATCGTGGAAATG & AAGTCCATCATCGTTGTTCATACA \\
\hline Jak2 & AGGCGACGGGAACAAGATGT & AGGCCATTCCCATCTAGAGC \\
\hline Tnfa & CTGTGAAGGGAATGGGTGTT & TTGGACCCTGAGCCATAATC \\
\hline
\end{tabular}

In vivo metabolic analyses. Random blood glucose measurements were measured as previously described (76). Glucose (i.p., $1 \mathrm{~g} / \mathrm{kg}$ ) and insulin $(0.75 \mathrm{U} / \mathrm{kg}$ ) tolerance tests were performed as previously described (76).

Flow cytometry. Leukocytes were isolated from whole blood, and analyses of monocyte subpopulations were done by flow cytometry as previously described (77). Cells were incubated on ice for $30 \mathrm{~min}$ utes with fluorescently conjugated antibodies for cell surface markers: FITC anti-mouse Ly-6C (clone AL-21; BD Pharmigen), anti-CD115-APC (clone AFS98; eBioscience), and anti-mouse cd45 (clone EF-450; BD Pharmigen). Data were acquired on an LSRII flow cytometer (BD Biosciences) and analyzed with FlowJo v7.6.1.

In vivo treatment with IGF-1. Sterile Alzet osmotic pumps (Alzet, type 2004, Durect Corporation) were inserted s.c. into 8-week-old mice while anesthetized with isoflurane (55). The minipumps provided a constant infusion $\left(0.11 \mu \mathrm{l} / \mathrm{hr}\right.$ ) of vehicle (saline $+10 \mathrm{mmol}^{-1}$ hydrochloric acid $(\mathrm{HCl})$ or Long R3 IGF-1 $(1.0 \mathrm{mg} / \mathrm{kg} / \mathrm{d}$; GroPep Bioreagents), a biologically active IGF-1 derivative. Long R3 IGF-1 or vehicle was administered for 12 weeks while mice were fed an atherogenic diet containing $0.2 \%$ cholesterol (TD88137, Harlan Laboratories). Minipumps were replaced every 28 days. Mice were housed individually and euthanized at the end of 12 weeks for analysis.

Quantitative PCR. Total RNA from liver tissue and aortic arches were isolated using Trizol reagent (Invitrogen). RNA was reverse-transcribed with random primers using M-MLV enzyme (Invitrogen). Quantitative PCR (qPCR) was performed using specific primers and SYBR Green master mix on a 7900HT Fast-Real-Time PCR System (Applied Biosystems). The relative mRNA abundance of each gene was normalized to the expression levels of $18 \mathrm{~S}$ as previously described (78). Primer sequences are listed in Table 1.

Statistics. Data are presented as mean \pm SEM. Statistical tests were carried out using GraphPad Prism version 5 (GraphPad Software). For comparison of data between 2 groups, 2-tailed independent-sample Student's $t$ test was performed, where applicable. For comparison among multiple groups, one-way ANOVA with post hoc Newman-Keuls multiple comparison test was performed, where applicable. Statistical significance was defined as $P<0.05$.

Study approval. All experiments using mice in this study were approved by the Toronto General Research Institute Animal Care Committee (AUP 2862).

\section{Author contributions}

TS, JL, MPB, CSR, RPB, and MW designed the research studies; KUW provided the mice; TS, SAS, AL, SYS, RB, DWD, AHM, APK, and JJB conducted the experiments; TS, AL, RB, and MW analyzed the data; TS, CTL, SYS, MPB, and MW wrote and reviewed the manuscript.

\section{Acknowledgments}

This work was supported by operating grants from the Canadian Institute of Health Research (CIHR) MOP-142193 and the Heart and Stroke Foundation of Canada to MW. MW is supported by the Canada Research Chair in Signal Transduction in Diabetes Pathogenesis. TS and SYS were supported by the CIHR Doctoral Research Award, the Canadian Diabetes Association (CDA) Doctoral Student Research Award, the Canadian Liver Foundation Graduate Studentship, and the Banting and Best Diabetes Centre (BBDC) Novo Nordisk Studentship. AL is supported by the Heart \& Stroke/Richard Lewar Centre of Excellence 
Studentship. CTL is supported by the Eliot Phillipson Clinician Scientist Training Program and postdoctoral fellowships from the CDA and BBDC.

Address correspondence to: Minna Woo, MaRS Centre, Toronto Medical Discovery Tower, 101 College Street, 10th floor, Room 10-361, Toronto, Ontario M5G 1L7 Canada. Phone: 416.581.7531; Email: mwoo@uhnresearch.ca.

1. Blum CB, Levy RI. Role of dietary intervention in the primary prevention of coronary heart disease. Individuals with high-normal or elevated serum cholesterol levels should be placed on cholesterol-lowering diets. Cardiology. 1987;74(1):2-21.

2. Plump AS, et al. Severe hypercholesterolemia and atherosclerosis in apolipoprotein E-deficient mice created by homologous recombination in ES cells. Cell. 1992;71(2):343-353.

3. Willerson JT, Ridker PM. Inflammation as a cardiovascular risk factor. Circulation. 2004;109(21 Suppl 1):II2-I10.

4. Steinberg D. Atherogenesis in perspective: hypercholesterolemia and inflammation as partners in crime. Nat Med. 2002;8(11):1211-1217.

5. Kuller LH, Tracy RP, Shaten J, Meilahn EN. Relation of C-reactive protein and coronary heart disease in the MRFIT nested case-control study. Multiple Risk Factor Intervention Trial. Am J Epidemiol. 1996;144(6):537-547.

6. Ridker PM, Hennekens CH, Buring JE, Rifai N. C-reactive protein and other markers of inflammation in the prediction of cardiovascular disease in women. $N$ Engl J Med. 2000;342(12):836-843.

7. Johnson BD, et al. Serum amyloid A as a predictor of coronary artery disease and cardiovascular outcome in women: the National Heart, Lung, and Blood Institute-Sponsored Women's Ischemia Syndrome Evaluation (WISE). Circulation. 2004;109(6):726-732.

8. Rane SG, Reddy EP. Janus kinases: components of multiple signaling pathways. Oncogene. 2000;19(49):5662-5679.

9. Yang X, et al. The role of the JAK2-STAT3 pathway in pro-inflammatory responses of EMF-stimulated N9 microglial cells. J Neuroinflammation. 2010;7:54

10. Baxter EJ, et al. Acquired mutation of the tyrosine kinase JAK2 in human myeloproliferative disorders. Lancet. 2005;365(9464):1054-1061.

11. Guo D, Li JR, Wang Y, Lei LS, Yu CL, Chen NN. Cyclovirobuxinum D suppresses lipopolysaccharide-induced inflammatory responses in murine macrophages in vitro by blocking JAK-STAT signaling pathway. Acta Pharmacol Sin. 2014;35(6):770-778.

12. Hansson GK, Hermansson A. The immune system in atherosclerosis. Nat Immunol. 2011;12(3):204-212.

13. Ross R. Atherosclerosis--an inflammatory disease. N Engl J Med. 1999;340(2):115-126.

14. Grote K, Luchtefeld M, Schieffer B. JANUS under stress--role of JAK/STAT signaling pathway in vascular diseases. Vascul Pharmacol. 2005;43(5):357-363.

15. Hasselbalch HC. Perspectives on chronic inflammation in essential thrombocythemia, polycythemia vera, and myelofibrosis: is chronic inflammation a trigger and driver of clonal evolution and development of accelerated atherosclerosis and second cancer? Blood. 2012;119(14):3219-3225.

16. Muendlein A, et al. Occurrence of the JAK2 V617F mutation in patients with peripheral arterial disease. Am J Hematol. 2015;90(1):E17-E21.

17. Gharavi NM, et al. Role of the Jak/STAT pathway in the regulation of interleukin- 8 transcription by oxidized phospholipids in vitro and in atherosclerosis in vivo. J Biol Chem. 2007;282(43):31460-31468.

18. Kirabo A, Oh SP, Kasahara H, Wagner KU, Sayeski PP. Vascular smooth muscle Jak2 deletion prevents angiotensin II-mediated neointima formation following injury in mice. J Mol Cell Cardiol. 2011;50(6):1026-1034.

19. Kirabo A, et al. Vascular smooth muscle Jak2 mediates angiotensin II-induced hypertension via increased levels of reactive oxygen species. Cardiovasc Res. 2011;91(1):171-179.

20. Quinton LJ, et al. Hepatocyte-specific mutation of both NF-кB RelA and STAT3 abrogates the acute phase response in mice. $J$ Clin Invest. 2012;122(5):1758-1763.

21. Sakamori R, et al. Signal transducer and activator of transcription 3 signaling within hepatocytes attenuates systemic inflammatory response and lethality in septic mice. Hepatology. 2007;46(5):1564-1573.

22. Sos BC, et al. Abrogation of growth hormone secretion rescues fatty liver in mice with hepatocyte-specific deletion of JAK2. J Clin Invest. 2011;121(4):1412-1423.

23. Shi SY, et al. Hepatocyte-specific deletion of Janus kinase 2 (JAK2) protects against diet-induced steatohepatitis and glucose intolerance. J Biol Chem. 2012;287(13):10277-10288.

24. Higashi Y, Pandey A, Goodwin B, Delafontaine P. Insulin-like growth factor-1 regulates glutathione peroxidase expression and activity in vascular endothelial cells: Implications for atheroprotective actions of insulin-like growth factor-1. Biochim Biophys Acta. 2013;1832(3):391-399.

25. Isenovi囚 E, Muniyappa R, Milivojevi囚 N, Rao Y, Sowers JR. Role of PI3-kinase in isoproterenol and IGF-1 induced ecNOS activity. Biochem Biophys Res Commun. 2001;285(4):954-958.

26. Renier G, Clément I, Desfaits AC, Lambert A. Direct stimulatory effect of insulin-like growth factor-I on monocyte and macrophage tumor necrosis factor-alpha production. Endocrinology. 1996;137(11):4611-4618

27. Hochberg Z, Hertz P, Maor G, Oiknine J, Aviram M. Growth hormone and insulin-like growth factor-I increase macrophage uptake and degradation of low density lipoprotein. Endocrinology. 1992;131(1):430-435.

28. Zhu B, Zhao G, Witte DP, Hui DY, Fagin JA. Targeted overexpression of IGF-I in smooth muscle cells of transgenic mice enhances neointimal formation through increased proliferation and cell migration after intraarterial injury. Endocrinology. 2001;142(8):3598-3606.

29. Kim M, Hwang EC, Park IK, Park K. Insulin-like growth factor-1 gene delivery may enhance the proliferation of human corpus cavernosal smooth muscle cells. Urology. 2010;76(2):511.e5-511.e9. 
30. Li Y, Higashi Y, Itabe H, Song YH, Du J, Delafontaine P. Insulin-like growth factor-1 receptor activation inhibits oxidized LDL-induced cytochrome $\mathrm{C}$ release and apoptosis via the phosphatidylinositol 3 kinase/Akt signaling pathway. Arterioscler Thromb Vasc Biol. 2003;23(12):2178-2184.

31. von der Thüsen JH, et al. IGF-1 has plaque-stabilizing effects in atherosclerosis by altering vascular smooth muscle cell phenotype. Am J Pathol. 2011;178(2):924-934.

32. Shai SY, Sukhanov S, Higashi Y, Vaughn C, Kelly J, Delafontaine P. Smooth muscle cell-specific insulin-like growth factor-1 overexpression in Apoe-/- mice does not alter atherosclerotic plaque burden but increases features of plaque stability. Arterioscler Thromb Vasc Biol. 2010;30(10):1916-1924.

33. Hirai H, Kanaya R, Maeda M, Qungfang D, Ina K, Hayashi T. The role of insulin growth factor on atherosclerosis and endothelial function: the effect on hyperlipidemia and aging. Life Sci. 2011;88(9-10):425-431.

34. Harrington SC, Simari RD, Conover CA. Genetic deletion of pregnancy-associated plasma protein-A is associated with resistance to atherosclerotic lesion development in apolipoprotein E-deficient mice challenged with a high-fat diet. Circ Res. 2007;100(12):1696-1702.

35. Swirski FK, et al. Ly-6Chi monocytes dominate hypercholesterolemia-associated monocytosis and give rise to macrophages in atheromata. J Clin Invest. 2007;117(1):195-205.

36. Udy GB, et al. Requirement of STAT5b for sexual dimorphism of body growth rates and liver gene expression. Proc Natl Acad Sci U S A. 1997;94(14):7239-7244.

37. Teglund S, et al. Stat5a and Stat $5 \mathrm{~b}$ proteins have essential and nonessential, or redundant, roles in cytokine responses. Cell. 1998;93(5):841-850.

38. Agrawal S, Gollapudi S, Su H, Gupta S. Leptin activates human B cells to secrete TNF- $\alpha$, IL-6, and IL-10 via JAK2/STAT3 and p38MAPK/ERK1/2 signaling pathway. J Clin Immunol. 2011;31(3):472-478.

39. Wang Y, van Boxel-Dezaire AH, Cheon H, Yang J, Stark GR. STAT3 activation in response to IL-6 is prolonged by the binding of IL-6 receptor to EGF receptor. Proc Natl Acad Sci U S A. 2013;110(42):16975-16980.

40. Mariño G, et al. Insulin-like growth factor 1 treatment extends longevity in a mouse model of human premature aging by restoring somatotroph axis function. Proc Natl Acad Sci U S A. 2010;107(37):16268-16273.

41. Wu Y, Sun H, Yakar S, LeRoith D. Elevated levels of insulin-like growth factor (IGF)-I in serum rescue the severe growth retardation of IGF-I null mice. Endocrinology. 2009;150(9):4395-4403.

42. Kawachi S, et al. Circulating insulin-like growth factor-1 and insulin-like growth factor binding protein-3 are associated with early carotid atherosclerosis. Arterioscler Thromb Vasc Biol. 2005;25(3):617-621.

43. Andreassen M, Raymond I, Kistorp C, Hildebrandt P, Faber J, Kristensen LØ. IGF1 as predictor of all cause mortality and cardiovascular disease in an elderly population. Eur J Endocrinol. 2009;160(1):25-31.

44. Fischer F, et al. Associations of insulin-like growth factors, insulin-like growth factor binding proteins and acid-labile subunit with coronary heart disease. Clin Endocrinol (Oxf). 2004;61(5):595-602.

45. Martin RM, et al. Associations of insulin-like growth factor (IGF)-I, IGF-II, IGF binding protein (IGFBP)-2 and IGFBP3 with ultrasound measures of atherosclerosis and plaque stability in an older adult population. J Clin Endocrinol Metab. 2008;93(4):1331-1338.

46. Spallarossa P, et al. Insulin-like growth factor-I and angiographically documented coronary artery disease. Am J Cardiol. 1996;77(2):200-202.

47. van den Beld AW, Bots ML, Janssen JA, Pols HA, Lamberts SW, Grobbee DE. Endogenous hormones and carotid atherosclerosis in elderly men. Am J Epidemiol. 2003;157(1):25-31.

48. Juul A, Scheike T, Davidsen M, Gyllenborg J, Jørgensen T. Low serum insulin-like growth factor I is associated with increased risk of ischemic heart disease: a population-based case-control study. Circulation. 2002;106(8):939-944.

49. Ruidavets JB, et al. Effects of insulin-like growth factor 1 in preventing acute coronary syndromes: the PRIME study. Atherosclerosis. 2011;218(2):464-469.

50. Laughlin GA, Barrett-Connor E, Criqui MH, Kritz-Silverstein D. The prospective association of serum insulin-like growth factor I (IGF-I) and IGF-binding protein-1 levels with all cause and cardiovascular disease mortality in older adults: the Rancho Bernardo Study. J Clin Endocrinol Metab. 2004;89(1):114-120.

51. Burgers AM, et al. Meta-analysis and dose-response metaregression: circulating insulin-like growth factor I (IGF-I) and mortality. J Clin Endocrinol Metab. 2011;96(9):2912-2920.

52. Carlzon D, et al. Both low and high serum IGF-1 levels associate with increased risk of cardiovascular events in elderly men. $J$ Clin Endocrinol Metab. 2014;99(11):E2308-E2316.

53. Shai SY, Sukhanov S, Higashi Y, Vaughn C, Rosen CJ, Delafontaine P. Low circulating insulin-like growth factor I increases atherosclerosis in ApoE-deficient mice. Am J Physiol Heart Circ Physiol. 2011;300(5):H1898-H1906.

54. Svensson J, Sjögren K, Levin M, Borén J, Tivesten $\AA$, Ohlsson C. Increased diet-induced fatty streak formation in female mice with deficiency of liver-derived insulin-like growth factor-I. Endocrine. 2016;52(3):550-560.

55. Sukhanov S, et al. IGF-1 reduces inflammatory responses, suppresses oxidative stress, and decreases atherosclerosis progression in ApoE-deficient mice. Arterioscler Thromb Vasc Biol. 2007;27(12):2684-2690.

56. Liang S, Hu Y, Liu C, Qi J, Li G. Low insulin-like growth factor 1 is associated with low high-density lipoprotein cholesterol and metabolic syndrome in Chinese nondiabetic obese children and adolescents: a cross-sectional study. Lipids Health Dis. 2016;15:112.

57. Sandberg EM, Wallace TA, Godeny MD, VonDerLinden D, Sayeski PP. Jak2 tyrosine kinase: a true jak of all trades? Cell Biochem Biophys. 2004;41(2):207-232.

58. Waters MJ, Brooks AJ. JAK2 activation by growth hormone and other cytokines. Biochem J. 2015;466(1):1-11.

59. Angelin B, Rudling M. Growth hormone and hepatic lipoprotein metabolism. Curr Opin Lipidol. 1994;5(3):160-165.

60. Nishizawa H, Takahashi M, Fukuoka H, Iguchi G, Kitazawa R, Takahashi Y. GH-independent IGF-I action is essential to prevent the development of nonalcoholic steatohepatitis in a GH-deficient rat model. Biochem Biophys Res Commun. 2012;423(2):295-300.

61. Pérez R, et al. Mitochondrial protection by low doses of insulin-like growth factor- I in experimental cirrhosis. World J Gastroen- 
terol. 2008;14(17):2731-2739.

62. Fan Y, et al. Liver-specific deletion of the growth hormone receptor reveals essential role of growth hormone signaling in hepatic lipid metabolism. J Biol Chem. 2009;284(30):19937-19944.

63. Arturi F, et al. Nonalcoholic fatty liver disease is associated with low circulating levels of insulin-like growth factor-I. J Clin Endocrinol Metab. 2011;96(10):E1640-E1644.

64. Völzke H, et al. Association between hepatic steatosis and serum IGF1 and IGFBP-3 levels in a population-based sample. Eur $J$ Endocrinol. 2009;161(5):705-713.

65. Liang S, Cheng X, Hu Y, Song R, Li G. Insulin-like growth factor 1 and metabolic parameters are associated with nonalcoholic fatty liver disease in obese children and adolescents. Acta Paediatr. 2017;106(2):298-303.

66. Matz-Soja M, et al. Hepatic Hedgehog signaling contributes to the regulation of IGF1 and IGFBP1 serum levels. Cell Commun Signal. 2014;12:11.

67. Wan X, et al. Dietary protein-induced hepatic IGF-1 secretion mediated by PPAR $\gamma$ activation. PLoS One. 2017;12(3):e0173174.

68. Inagaki T, Lin VY, Goetz R, Mohammadi M, Mangelsdorf DJ, Kliewer SA. Inhibition of growth hormone signaling by the fasting-induced hormone FGF21. Cell Metab. 2008;8(1):77-83.

69. Gholamhosseini S, et al. $\omega-3$ fatty acid differentially modulated serum levels of IGF1 and IGFBP3 in men with CVD: a randomized, double-blind placebo-controlled study. Nutrition. 2015;31(3):480-484.

70. Bauman WA, La Fountaine MF, Cirnigliaro CM, Kirshblum SC, Spungen AM. Low-dose baclofen therapy raised plasma insulin-like growth factor-1 concentrations, but not into the normal range in a predictable and sustained manner in men with chronic spinal cord injury. J Spinal Cord Med. 2013;36(5):476-482.

71. Braverman ER, et al. Adult growth hormone deficiency treatment with a combination of growth hormone and insulin-like growth factor-1 resulting in elevated sustainable insulin-like growth factor-1 and insulin-like growth factor binding protein 3 plasma levels: a case report. JMed Case Rep. 2010;4:305.

72. Franco C, et al. Discoidin domain receptor 1 (ddr1) deletion decreases atherosclerosis by accelerating matrix accumulation and reducing inflammation in low-density lipoprotein receptor-deficient mice. Circ Res. 2008;102(10):1202-1211.

73. Lopes J, et al. Type VIII collagen mediates vessel wall remodeling after arterial injury and fibrous cap formation in atherosclerosis. Am J Pathol. 2013;182(6):2241-2253.

74. Kitson AP, et al. Effect of dietary docosahexaenoic acid (DHA) in phospholipids or triglycerides on brain DHA uptake and accretion. J Nutr Biochem. 2016;33:91-102.

75. Shi SY, et al. DJ-1 links muscle ROS production with metabolic reprogramming and systemic energy homeostasis in mice. Nat Commun. 2015;6:7415

76. Wang L, et al. Pten deletion in RIP-Cre neurons protects against type 2 diabetes by activating the anti-inflammatory reflex. Nat Med. 2014;20(5):484-492.

77. Ensan S, et al. Self-renewing resident arterial macrophages arise from embryonic CX3CR1(+) precursors and circulating monocytes immediately after birth. Nat Immunol. 2016;17(2):159-168.

78. Choi D, et al. Erythropoietin protects against diabetes through direct effects on pancreatic beta cells. JExp Med. 2010;207(13):2831-2842. 